\title{
Application of 3D Seismic Signal and Geomechanical Attributes for Subsurface Fracture Characterization: A Case Study in Clearfield County, Central Pennsylvania
}

Iman F. Zulkapeli

West Virginia University, nazulkapeli@mix.wvu.edu

Follow this and additional works at: https://researchrepository.wvu.edu/etd

Part of the Geological Engineering Commons, Geology Commons, and the Geophysics and Seismology Commons

\section{Recommended Citation}

Zulkapeli, Iman F., "Application of 3D Seismic Signal and Geomechanical Attributes for Subsurface Fracture Characterization: A Case Study in Clearfield County, Central Pennsylvania" (2021). Graduate Theses, Dissertations, and Problem Reports. 8042.

https://researchrepository.wvu.edu/etd/8042

This Thesis is protected by copyright and/or related rights. It has been brought to you by the The Research Repository @ WVU with permission from the rights-holder(s). You are free to use this Thesis in any way that is permitted by the copyright and related rights legislation that applies to your use. For other uses you must obtain permission from the rights-holder(s) directly, unless additional rights are indicated by a Creative Commons license in the record and/ or on the work itself. This Thesis has been accepted for inclusion in WVU Graduate Theses, Dissertations, and Problem Reports collection by an authorized administrator of The Research Repository @ WVU. For more information, please contact researchrepository@mail.wvu.edu. 
Application of 3D Seismic Signal and Geomechanical Attributes for Subsurface Fracture Characterization: A Case Study in Clearfield County, Central Pennsylvania.

Iman F. Zulkapeli

Thesis submitted

to the Eberly College of Arts and Sciences

at West Virginia University

in partial fulfillment of the requirements for the degree of

Master of Science in

Geology

\author{
Dengliang Gao, Ph.D., Chair \\ Tim Carr, Ph.D. \\ Amy Weislogel, Ph.D.
}

Department of Geology and Geography

Morgantown, West Virginia

2021

Keywords: 3D seismic, seismic attributes, geology, geophysics, geomechanics, unconventional reservoir, hydrocarbon

Copyright 2021 Iman Zulkapeli 


\section{ABSTRACT \\ Application of 3D Seismic Signal and Geomechanical Attributes for Subsurface \\ Fracture Characterization: A Case Study in Clearfield County, Central Pennsylvania.}

\section{Iman F. Zulkapeli}

Hydrocarbon exploration in unconventional reservoirs is highly risky due to the nature of the reservoirs and the variability in fractures and reservoir geomechanical properties in the subsurface. The reservoir needs to be fully characterized to avoid any complication such as frac hit, wellbore failure, blowout, or even a dry hole. The Clearfield reservoir produces an exceptionally low amount of gas, compared to the neighboring region in the proximity, which has been poorly understood. This raises the question as to what causes the reservoir to have low productivity.

This study focuses on the natural fracture characterization using high-quality $3 \mathrm{D}$ seismic signal attributes. The structural discontinuities of this unconventional reservoir are characterized using multiple 3D seismic attributes such as maximum curvature, anttracking, and sweetness. Maximum curvature attributes allow us to visualize the intensity of the faults and fractures. This study finds that the Marcellus Shale horizon has the most intense faults with no preferred orientation. Ant-tracking is another useful attribute in determining the potential path for hydrocarbon migration. It detects and traces the connecting fractures known as fracture swamps. It is proven that this reservoir is dominated by high angle faults and fracture swarms, which may have contributed to its low productivity.

Well log data is incorporated in order to calibrate with the seismic data. Young's Modulus (YME) and Poisson's Ratio (PR) values are measured based on the sonic logs. The ratio of YME and PR are then calculated from one of the horizontal wells to obtain the brittleness value of the Marcellus Shale. This study finds that within the Marcellus Shale horizon, the geomechanical properties and brittleness values vary due to the abundance of faults and fractures. The Marcellus Shale in this reservoir is in fact anisotropy. In addition to that, the complex fracture networks in the Clearfield gas field could be detrimental to the reservoir integrity, thus lowering the gas productivity. 


\section{ACKNOWLEDGEMENTS}

Firstly, I would like to express my deepest appreciation to my committee members Dr. Dengliang Gao, Dr. Tim Carr, and Dr. Amy Weislogel. Thank you, Dr. Gao, for the research opportunity and invaluable advice throughout my research journey. I appreciate the overwhelming support over the past years. I've gained an enormous amount of knowledge from Dr. Carr regarding reservoir geomechanics from his classes and I am thankful for that. Next, I am grateful for the tremendous help and support from Dr. Weislogel throughout my research.

I would like to thank the Department of Geology and Geography for the research opportunity and the funding throughout my graduate years. A huge thank you to the IT department for their assistance with the software and computer support, which was crucial to the major portion of my research. I am also thankful for my colleagues Tobi Ore, Mohammad Faiq Adenan, and Namiko Michada, for the tremendous input and support. I am grateful for my parents Zulkapeli Saban and Ummi Ismail for always believing in me and supporting me. I am also blessed for my siblings and close friends that I have made and met along the way. I truly appreciate the support I have received throughout my undergraduate and graduate studies at West Virginia University.

Lastly, thanks to Greylock Energy LLC for providing me with the 3D seismic data and well logs for this research. 


\section{TABLE OF CONTENTS}

ABSTRACT

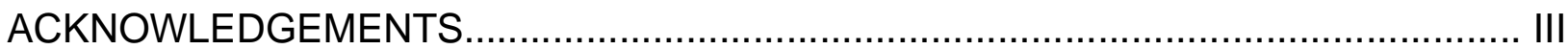

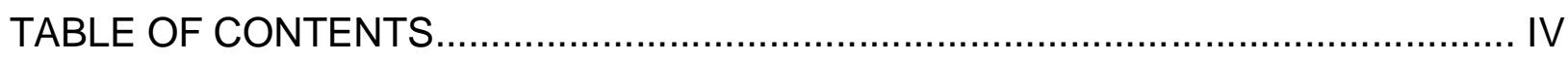

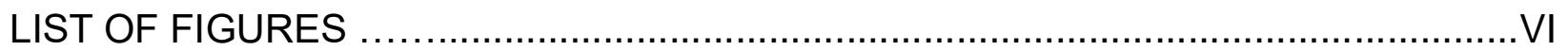

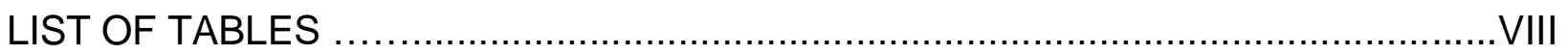

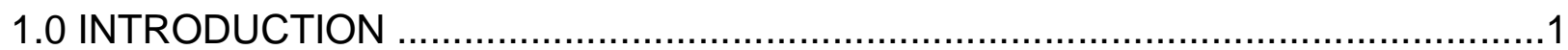

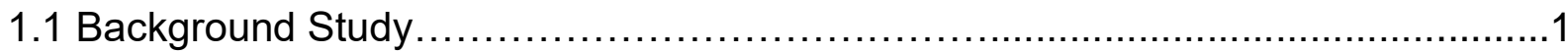

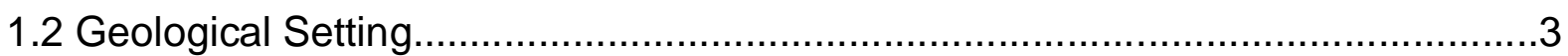

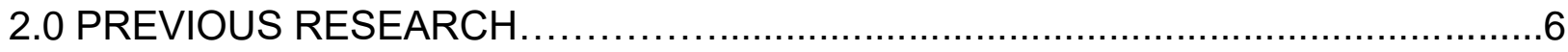

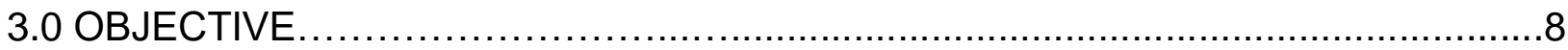

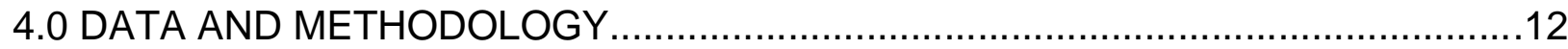

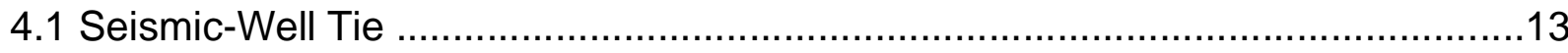

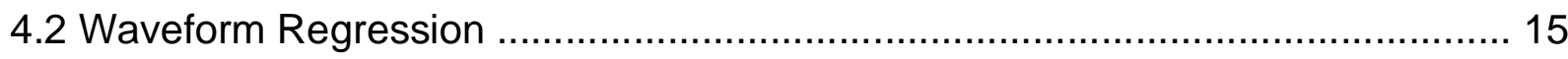

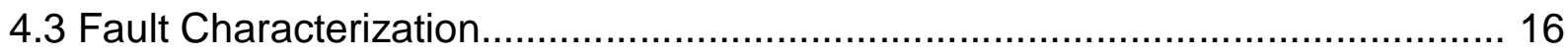

4.3.1 Fault/Fracture Detection Using Variance and Maximum Curvature...............16

4.3.2 Fracture Swarms Detection Using Ant-Tracking.....................................17 
4.3.3 Fracture and Hydrocarbon Detection Using Sweetness.

4.3.4 Fracture Orientation Using Dip \& Azimuth and Histogram..........................19

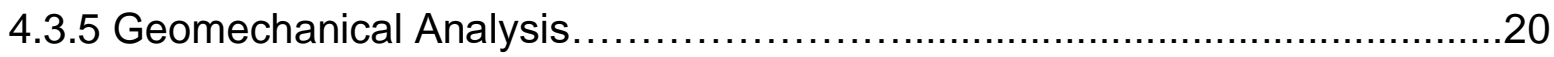

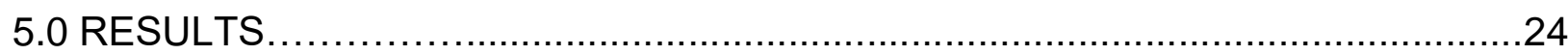

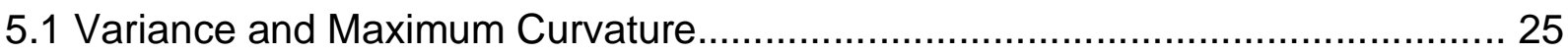

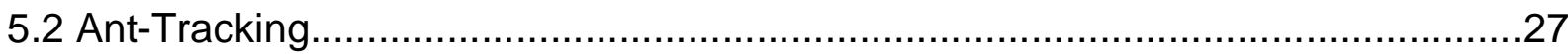

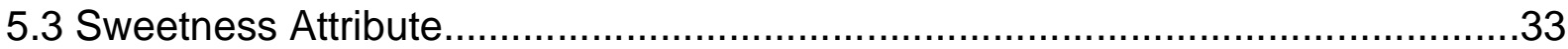

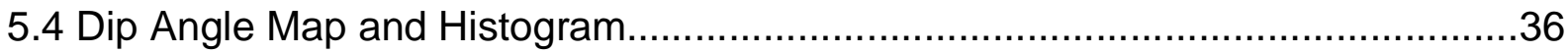

5.5 Dip Azimuth Map and Histogram................................................................

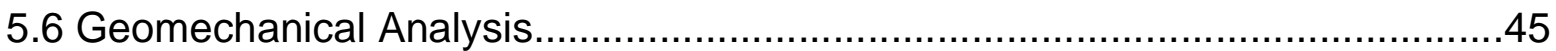

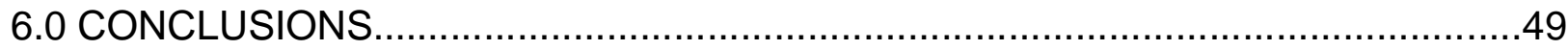

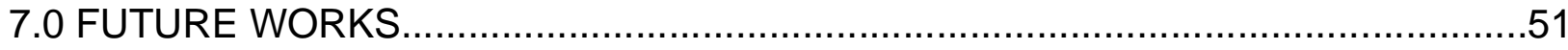

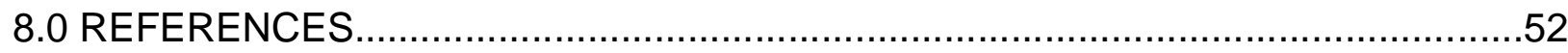




\section{LIST OF FIGURES}

FIGURE 1: Location map of the study area relative to the hinge of Pennsylvania

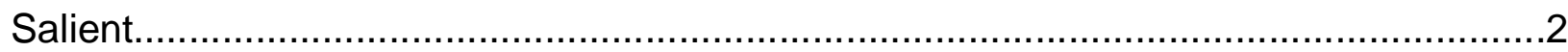

FIGURE 2: Bouguer gravity color-coded map .......................................................

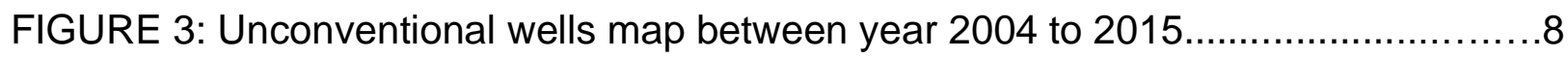

FIGURE 4: Time structures from the Base Silurian salt to the Middle Devonian Tully

Limestone

FIGURE 5: Waveform Model Regression attribute............................................15

FIGURE 6: Ant-tracking example in Clearfield.......................................................17

FIGURE 7: Graph of YME and PR compared to brittleness index (BI) and BI

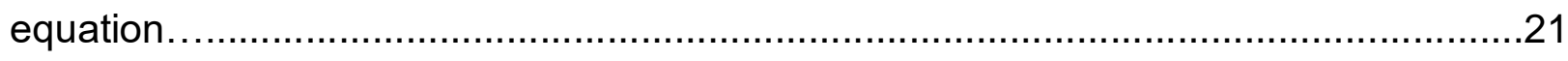

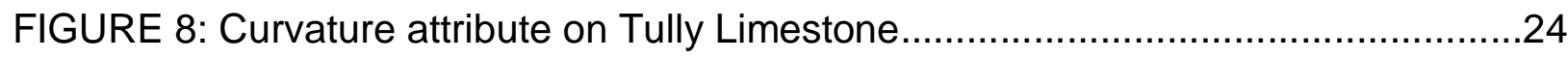

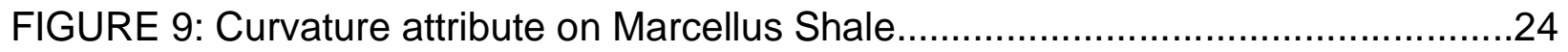

FIGURE 10: Curvature attribute on Onondaga Limestone........................................24

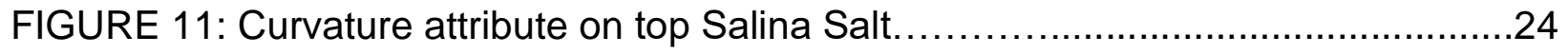

FIGURE 12: Curvature attribute on base Salina Salt..............................................25

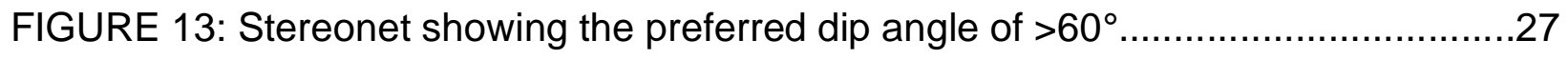

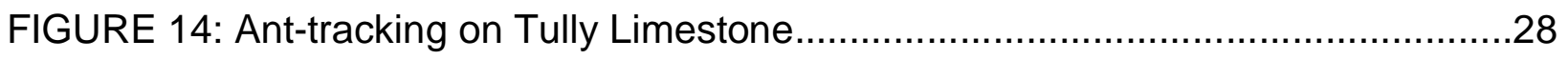


FIGURE 15: Ant-tracking on Marcellus Shale.

FIGURE 16: Ant-tracking on Onondaga Limestone.

FIGURE 17: Ant-tracking on top Salina Salt .28

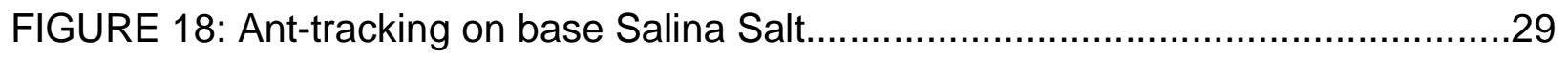

FIGURE 19: Ant-tracking on Marcellus with $60^{\circ}$ dip compared with $<30^{\circ}$ dip.............31

FIGURE 20: Sweetness map before scale adjustment...............................................34

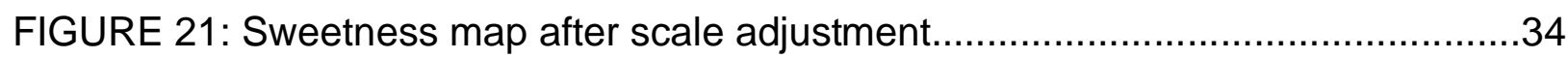

FIGURE 22: Dip angle map and histogram of Tully Limestone..................................36

FIGURE 23: Dip angle map and histogram of Marcellus Shale..................................36

FIGURE 24: Dip angle map and histogram of Onondaga Limestone...........................36

FIGURE 25: Dip angle map and histogram of top Salina Salt......................................

FIGURE 26: Dip angle map and histogram of base Salina Salt................................37

FIGURE 27: Dip azimuth, dip angle and strike diagram........................................40

FIGURE 28: Dip azimuth map and distribution of Tully Limestone..............................41

FIGURE 29: Dip azimuth map and distribution of Marcellus Shale..............................41

FIGURE 30: Dip azimuth map and distribution of Onondaga Limestone......................41

FIGURE 31: Dip azimuth map and distribution of top Salina Salt................................42

FIGURE 32: Dip azimuth map and distribution of base Salina Salt............................42 
FIGURE 33: The well log data of the horizontal well \#3703327221.

\section{LIST OF TABLES}

TABLE 1: Rock's elasticity versus YME and PR value...............................22

TABLE 2: Poisson's Ratio (PR), Young's Modulus (YME) and brittleness

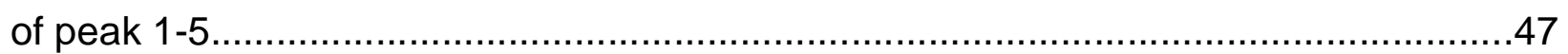




\section{Introduction}

\subsection{Background Study}

In hydrocarbon exploration, routinely, the structures and properties that bear significance to the productivity of the reservoir is sought to be characterized. These reservoirs have been broadly categorized as conventional or unconventional. Exploitation of unconventional reservoirs takes advantage of technologies, such as hydraulic fracturing, to stimulate existing fractures or create new ones. Generally, in an unconventional reservoir, its fracture abundance, intensity and orientation can boost or mitigate reservoir performance and hydrocarbon productivity. Fractures may be advantageous in certain reservoirs as they help release oil and gas trapped in the source rock. However, under some circumstances, fractures could also redirect and leak the hydrocarbon especially where fracture swarms are present. Fracture swarms are where fractures are clustered to become large scale fracture zones. This is why a thorough fracture characterization of a reservoir is important in understanding reservoir behavior. Applying 3D seismic attributes to visualize the fracture abundance, intensity and orientation will reveal how these parameters jointly affect the gas productivity of the Marcellus Shale reservoir in the Clearfield County region of central Pennsylvania (figure 1). 


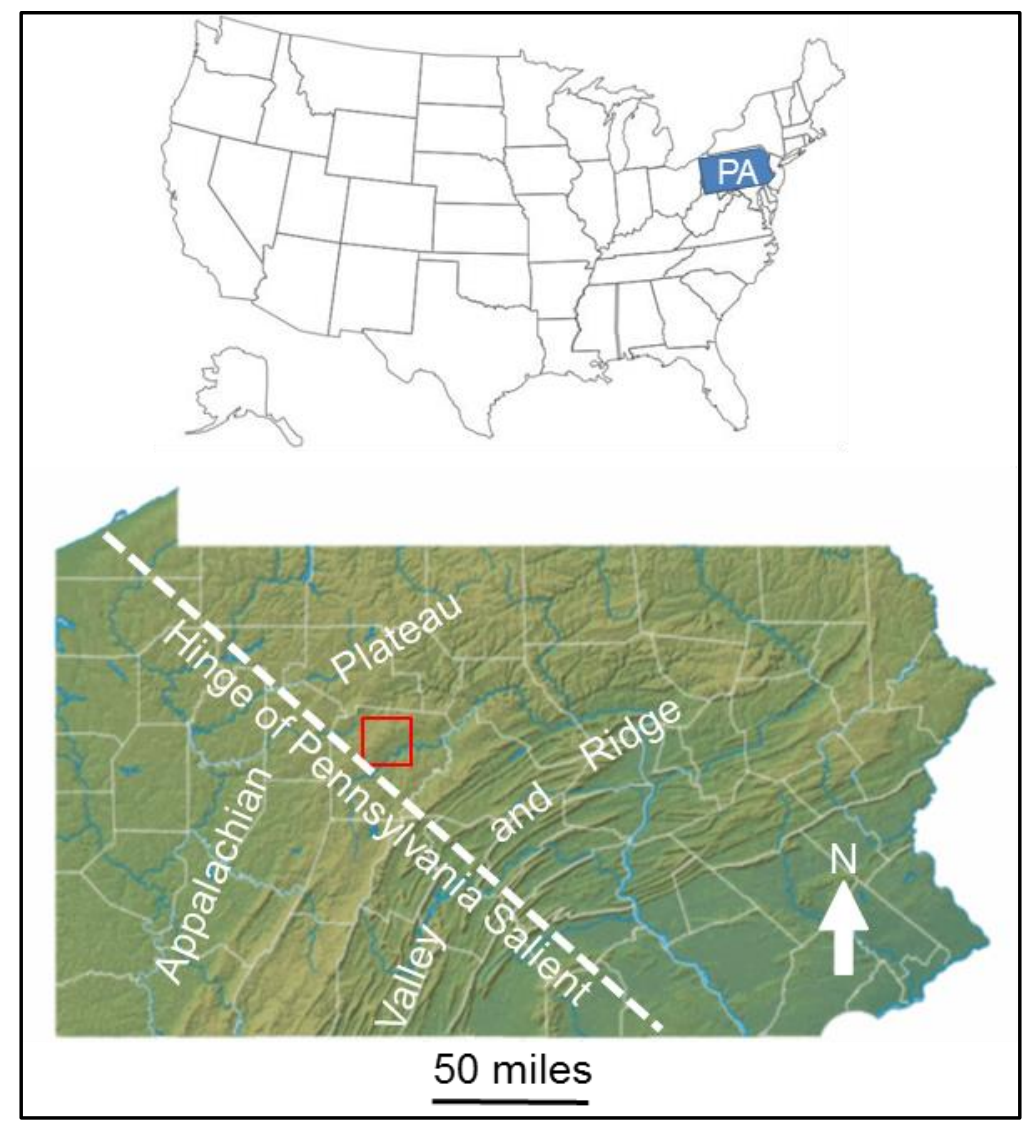

Figure 1: Location index map of the study area (red box) relative to the hinge of Pennsylvania salient

In Clearfield County, the Marcellus Shale gas production has been substantially low due to its proximity to the hinge zone of Pennsylvanian Salient (Gao et al., 2019). This is in contrasts with the high gas production in the southwestern and northeastern regions of Pennsylvania such as in Greene County, that is distant to the hinge of the Pennsylvania Salient. 


\subsection{Geological Setting}

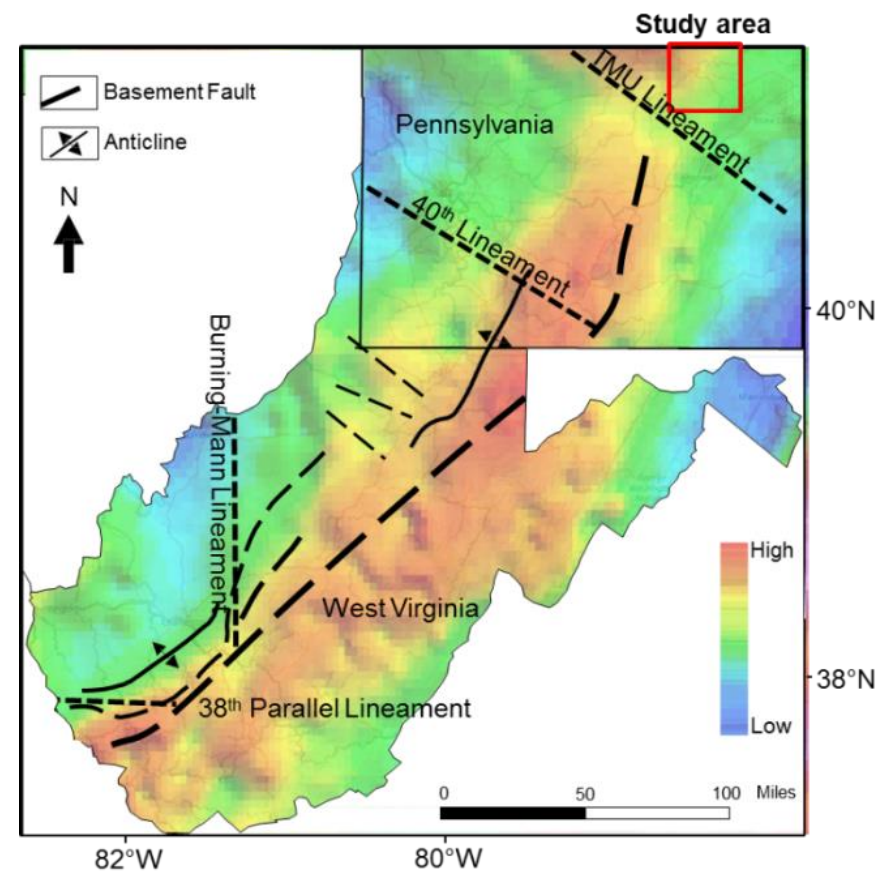

Figure 2: Bouguer gravity color-coded map (from https:// cellcode.us/quotes/states-mapunited-gravity.html)

The Bouguer gravity color-coded map above (Figure 2) shows major gravity gradients and inferred lineaments in south-central Pennsylvania and West Virginia and highlights the northeast- trending and the northwest-trending lineament. The Pennsylvania Salient, also known as the Pennsylvanian Bending, extends from the southern part of New York across Pennsylvania to Maryland. The Appalachian Mountains were formed 300 million years ago during the collision of the North American and the African continental plates. The North American plate was pushed westward during the collision, forcing the Appalachian Mountains to fold and thrust upwards (Barnestone, 2014). This caused the differential contraction and westward bending of mountain range. The westward bending has defined the structure of the study area that 
we see today. At the hinge of the bending, there are two sets of lineaments, the northeast trending (regional) and the northwest trending (cross-regional) ones. These lineaments have been the focus of research for many years (Gao and Shumaker, 1996).

Four tectonic orogenies known as Grenville, Taconic, Acadian and Allegheny occurred from the Ordovician through the Pennsylvanian. This series of deformation and deposition have contributed to the complex structures and stratigraphy in the Appalachian Plateau. The Grenville Orogeny (1000 Ma) has developed the basement floor under the Appalachian foreland (Kulander and Ryder, 2005). The rock has structures such as flow foliation, gneissic structures, and recumbent isoclinal folds which is synonymous with the pre-Cambrian compressional event (Shultz, 1999). The Grenville compression along with eastern interior extension has caused asymmetric extension in the basement that created multiple grabens with the biggest one called the Rome trough (Gao and Shumaker, 1996; Kulander and Ryder, 2005). Rome trough, also known as 'Post-Grenville' rifting, is the major rift system associated with the opening and spreading of the lapetus-Theic Ocean during the early and middle Cambrian (Gao and Shumaker, 1996).

Taconic orogeny, initiated later on during the Ordovician (450-490 Ma), features a series of subduction and erosion events. The subduction was caused by the collision of continental arcs with the eastern margin of Laurentia and was followed by an erosion in the late Silurian. During this erosion period, the sea transgressed causing a marine shelf environment for shale, carbonate and evaporite to deposit (Faill, 1997). 
The Acadian orogeny, occurred during Middle Devonian-Early Mississippian ( 425-390 Ma), was important to the evolution of the central Appalachian basin. A second influx of detrital sediment was introduced into the basin from orogenic highlands created by the Acadian orogeny that allowed for the Middle Devonian rock units, including the Onondaga Limestone and Marcellus Shale, to accumulate in basinal marine environments (Shultz, 1999).

The cycle of deformation and deposition peaked during the Alleghanian orogeny, which occurred during Late Mississippian-Late Permian. The collision of Gondwana and Peri-Gondwana continents had formed a complex deformation and subsequently created the supercontinent Pangea (Faill, 1997). 


\section{Previous Research}

Several researchers have studied the Marcellus Shale though the utilization of 3D seismic data and imaging techniques such as coring, microseismic, well logs and image logs. Frequency-enhanced waveform regression attributes were generated (Roberts, 2010; Bowers, 2014; Geiger, 2017; Gao et al., 2019) to help better delineate structures such as small fractures, fracture swarms, and more that were difficult to visualize in the original seismic image. With this visual enhancement, further interpretations were made to improve our understanding of hydrocarbon exploration in Pennsylvania (Donahoe and Gao, 2016). Roberts (2013) used the application of multiple seismic attributes to visualize the geological structures and focused on the application of seismic attributes to visualize structural contrast between underlying and overlying formations.

Greene County, located in southwest Pennsylvania, was extensively studied due to its high gas production (Donahoe and Gao, 2016; Gao, Donahoe, Duan and Sullivan, 2018). The structure styles of the region were scrutinized using 3D seismic data to understand the lateral and vertical variations that are spatially and temporally related to fold curvature and fault throw. The relation between the productivity of a region and its proximity to the regional (northeast trending) reverse faults was studied to understand their correlation. Isochron thickness and seismic facies maps are among few other maps that were generated in this study. Each seismic map is viewed in a map view in order to detect any variations within and across the reservoir formations. Based on their 
interpretation, they concluded that the regional reverse faults are affecting the productivity of gas in the region.

Clearfield County is an area that has a complex fault system (Shultz, 1999).

Therefore, the presence and distribution of unique and complex faults and fractures in the region need to be visualized and studied using innovative seismic attribute technologies. Although there are numerous studies in this region, fracture characterization was not studied in a quantitative manner. Since this region is located at the hinge zone, structural discontinuities are one of the most important aspects to be studied. 


\section{Objective}

The study area, Clearfield County, is intensively fractured with complex networks. The production data shows low productivity in this region compared to the neighboring regions with similar Marcellus Shale quality such as the maturity level, thickness and depth (Figure 3). This has led to the drilling of fewer wells for the exploitation of gas. This discrepancy is not fully understood and is a concern for both industries in the region and researchers. A possible hypothesis is that the productivity could be related to the presence of faults and fractures of certain orientation or intensity. Clearfield County has fractures with contrasting orientations, intensity, and complexity compared to the northeast and southwest regions.

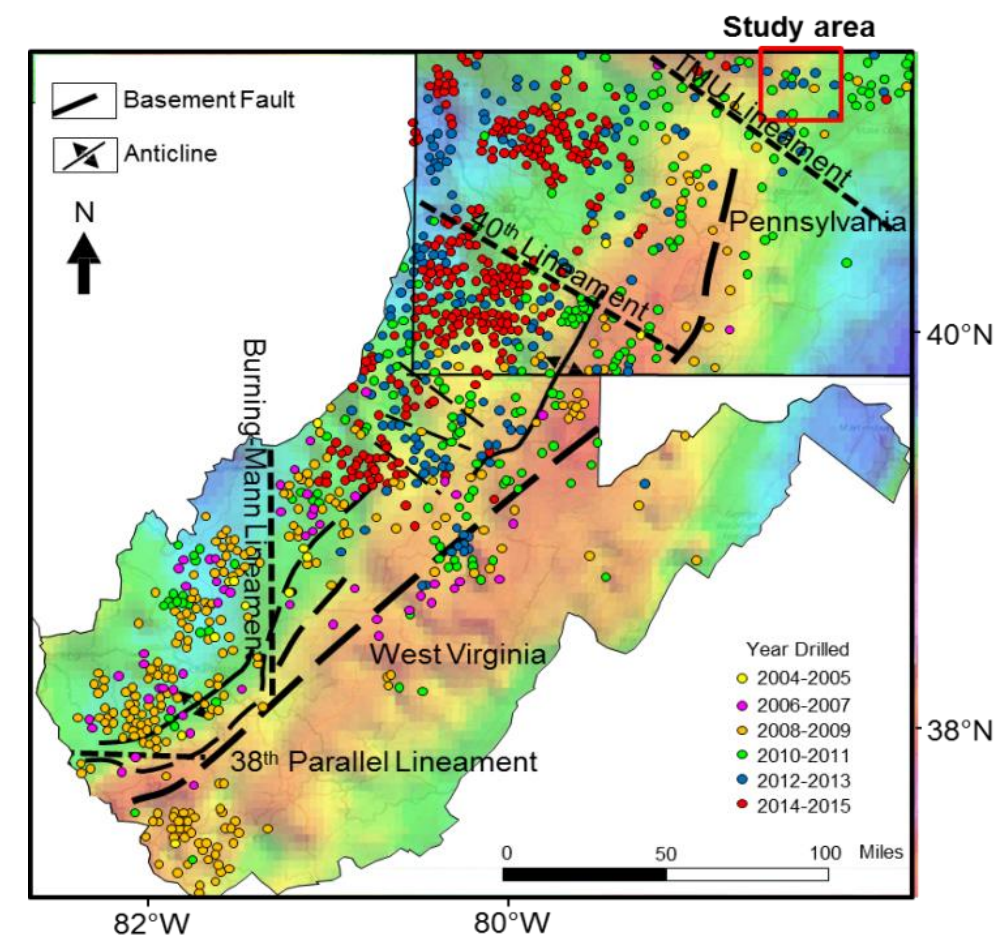

Figure 3: Unconventional wells map between year 2004 to 2015 (from Gao et al.,2020) 
Figure 3 shows unconventional wells that were completed from 2004 to 2015 in the Devonian interval overlaid with major faults and folds in south-central Pennsylvania and West Virginia, Appalachian Plateau (after Gao et al., 2018). The background shows Bouguer gravity intensity with the warm color denoting gravity high and the cold color denoting gravity low.

The objective of this study is to characterize the faults and fractures of formations in the reservoir in order to understand reservoir behavior. The variations in fracture intensity across the formations, which includes the Tully Limestone, Marcellus Shale, Onondaga Limestone, and Salina Salt will be analyzed. This paper will also characterize the fracture orientation, dip angle, and dip azimuth of each horizon to observe any distinct pattern of faults. The results will be shown in map and histogram form for visual and statistical analysis.

The variation in fault and fracture patterns will affect the reservoir's stability in one way or another. Geomechanical analysis is an important aspect to consider when planning for drilling of hydrocarbon reservoirs to avoid any complication during the process. Reservoirs with low mechanical stability will reduce its stability and cause wellbore failure (Sarem and Riahi, 2020). Young's Modulus and Poisson's Ratio are two of the elastic parameters that will be investigated at Clearfield wells to estimate and observe the changes of the reservoir strength relative to the proximity of the fractures in the region. 
Studies on a high productivity reservoir have been done extensively; however, this paper will examine the physical properties of a low productivity reservoir and how it affects the stability. It is important to understand the physical properties of both good and bad reservoirs because the goal here is to increase our understanding on reservoir behavior and to predict the quality of future potential reservoirs. The physical properties of the Clearfield reservoir could be used to predict the productivity of reservoirs that also have similar complexity of fracture networks.

The working hypothesis is the Clearfield reservoir rock contains abundant faults and fractures in certain orientations that contribute to its low productivity. Characterizing these faults and fractures would help us understand the properties of the low productivity reservoir in general. Understanding how certain fractures mitigate or enhance gas production allows us to apply 3D seismic analysis for reservoir characterization and forecasting. In addition to that, the rock brittleness within the Marcellus Shale might play a role in its structural variation.

In order to test the hypothesis and to achieve the goal, multiple 3D seismic attributes will be used to study the fracture properties present in the region in detail. First, the fractures will be visualized across all formations in cross-section using waveform model regression analysis to enhance seismic structural grains. Next, fracture intensity and abundance across all formations in time/horizon slices will be delineated using maximum curvature, dip angle, dip azimuth, ant-tracking, and sweetness attributes. These attributes are helpful for recognizing fracture connectivity and fracture swarms. The histogram of dip angle and azimuth will be generated for statistical 
interpretation. Lastly, the rock's brittleness will be evaluated by incorporating its geomechanical properties.

Using 3D seismic analysis to characterize fracture properties enables us to understand the reservoir and its productivity. Petrophysical and geomechanical properties of the reservoir can be measured by observing the style (contractional, shear or extensional), orientation (northeast or southwest), and size (large or small scale) of fractures. When viewed from the map view on horizon slice, the change of fracture properties over depth can be an indicator of where the fracture starts propagating and diminishing. It also helps us understand ways and to what degrees that it has affected the reservoir. This research could potentially help understand the contribution of fractures to reservoir performance and how it affects shale gas productivity. It is hoped that this study will lay a solid foundation for future researchers on unconventional shale reservoir characterization and forecasting. 


\section{Data and Methodology}

Figure 4 shows the time structures from the base Silurian salt denoted in green, through the top salt, Onondaga Limestone, Marcellus Shale and the Middle Devonian Tully Limestone. The colored lines indicate different rock layers as shown on the right side of the image. The figure below is a cross-section view of the reservoir in the study area viewed in a Northeast direction. The faults are northeast trending flat-top folds that can be seen on this seismic amplitude image.

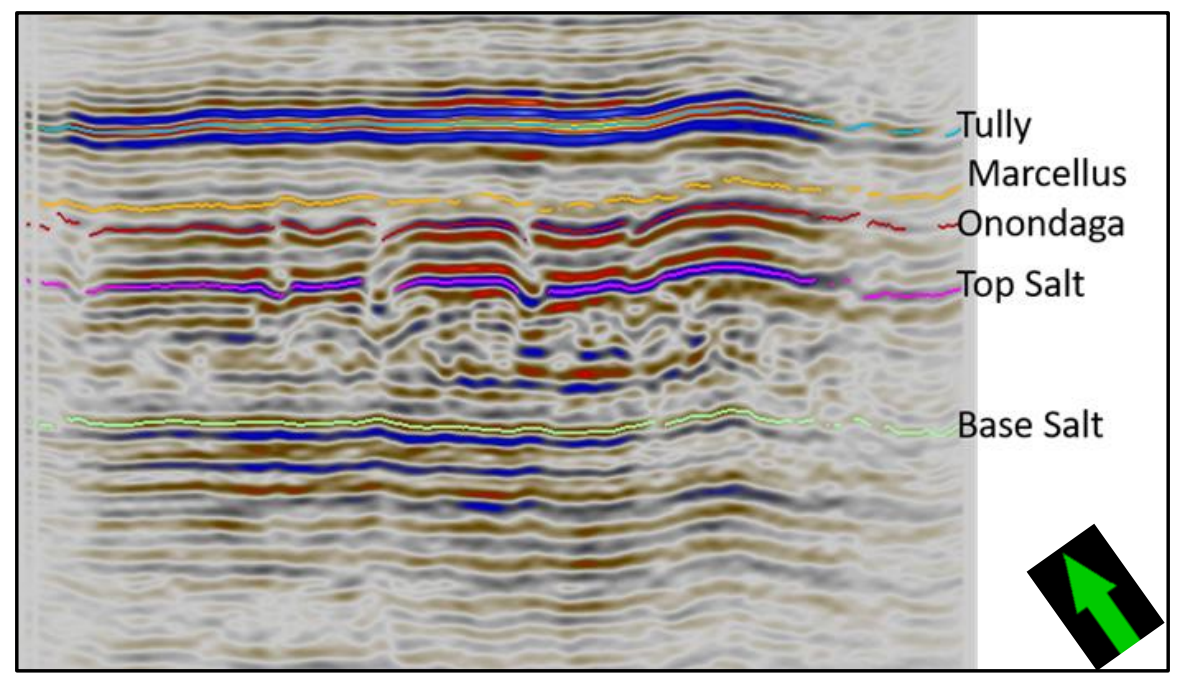

Figure 4: Time structures from the Base Silurian salt to the Middle Devonian Tully Limestone

In this study, a 30-square-mile 3D seismic survey was acquired over a gas field in Clearfield County, Central Pennsylvania. Energy companies have provided thirteen well log data and production data from both vertical and lateral wells for this study. The seismic reflection data were acquired with a lateral resolution bin size of 110 feet and a vertical sampling rate of 2 milliseconds. Gamma-ray log, sonic log, and few more were provided for most of the wells. Formations and lithologies were determined based on 
the interpretation of the log data provided. These well log data are then integrated into 3D seismic data to be used for interpretation using Petrel software developed by Schlumberger, using a technique called 'well-seismic calibration'. It is a method of correlating well log data with seismic data by marking each of the formation's top and base as a guide for horizon picking in seismic dataset. 


\subsection{Seismic-Well Tie}

A synthetic seismogram is generated to create well-seismic ties in order to correlate well data (hard data) with seismic data (soft data). The depth in feet from the log data will be calibrated with the depth in time (second) in seismic using the checkshot data. This is done because two-way time (TWT) is used as a unit of depth in 3D seismic, considering that the depth is calculated based on velocity. Therefore, for each horizon, the relative depth is expressed in milliseconds. Formation tops and bases are picked within the seismic data using this correlation. They must be picked precisely to make sure that interpretations afterward are accurate since this is a fundamental step of seismic analysis. The formations, also called the horizons, picked are Tully Limestone, Marcellus Shale, Onondaga Limestone, top and base of Salina Salt. Various attributes are applied to these selected horizons for fracture characterization and interpretation. 


\subsection{Waveform Regression}

Figure 5 demonstrates the Waveform Model Regression (WMR) analysis viewed in the northeast direction that with an enhanced image quality for fault detection. This attribute illuminates the discontinuities and enhance fault and fracture visualizations. The vertical pink lines drawn in figure 5 below indicate the vertical faults in the reservoir. As shown, the NE-trending (flat-top folds) regional faults below are the result of compressional force above the detachment horizon of the Salina Salt.

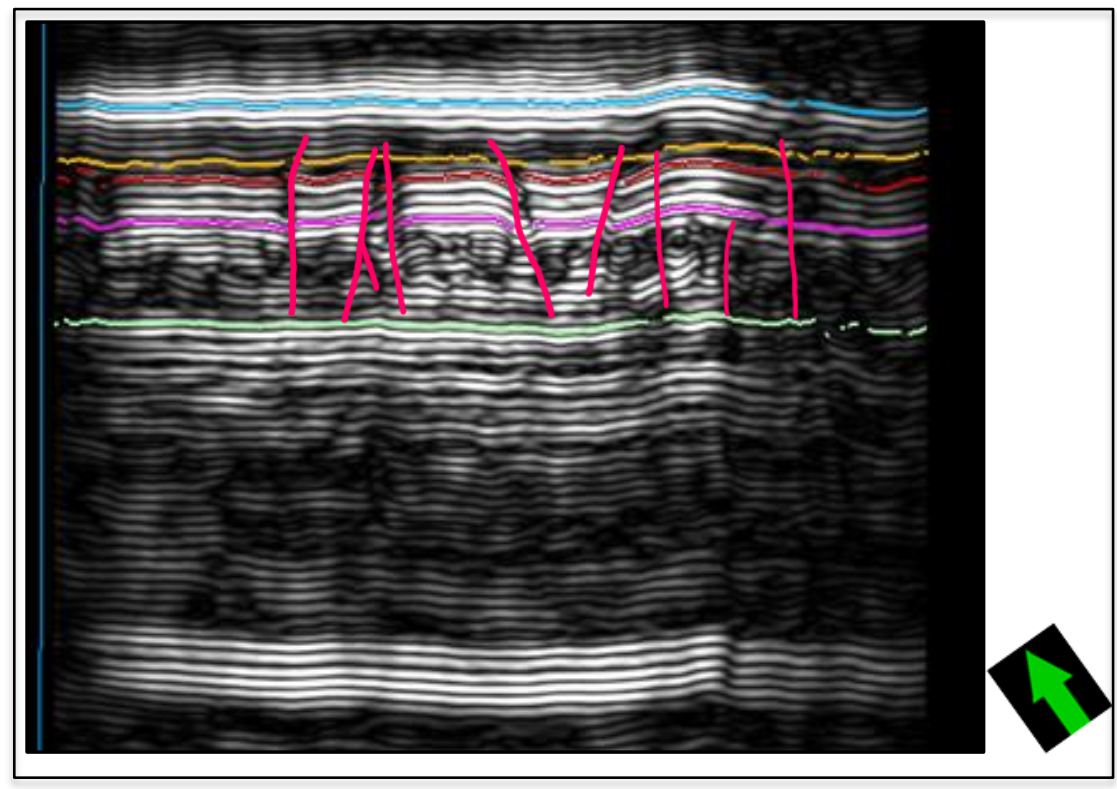

Figure 5: Waveform Model Regression attribute 


\subsection{Fault Characterization}

\subsubsection{Fault/Fracture Detection using Variance and Maximum Curvature}

The variance and maximum curvature attributes are applied for every horizon picked. Clearfield County has complex reservoir structures due to its proximity to the hinge of Pennsylvania Salient as aforementioned. Therefore, the migration path of hydrocarbon in the reservoir may be redirected. Variance attribute is a powerful tool for fracture visualization by allowing us to detect the coherency, which is the measure of continuity and similarity of the neighboring seismic traces. Minor differences in seismic signals would be an indicator of the presence of even small fractures.

Maximum curvature can also be used for describing reservoir geometry in terms of deformational intensity and paleo-stress orientation within the reservoir. By using this attribute, faults and fractures can be delineated to better understand and interpret the reservoir properties. 


\subsubsection{Fracture Swarms detection using Ant-Tracking}

Ant-Tracking is a volume attribute derived from machine learning that traces the connectivity of fractures based on the variance attribute from the previous method (by using variance as an input). The 'track', which typically aligned with the fractures, could be manipulated using the stereonet. It means that the intensity of fracture swarms can be controlled, and that provides an extent of flexibility. Fracture swarm is important because, firstly, it affect the reservoir pressure released, thus potentially lowering the reservoir pressure. Secondly, it may serve as a path for hydrocarbon migration in reservoirs. Figure 6 below is an example of ant-tracking on a layer in Clearfield. The bright blue color denotes the tracks in which the fractures are communicating with each other.

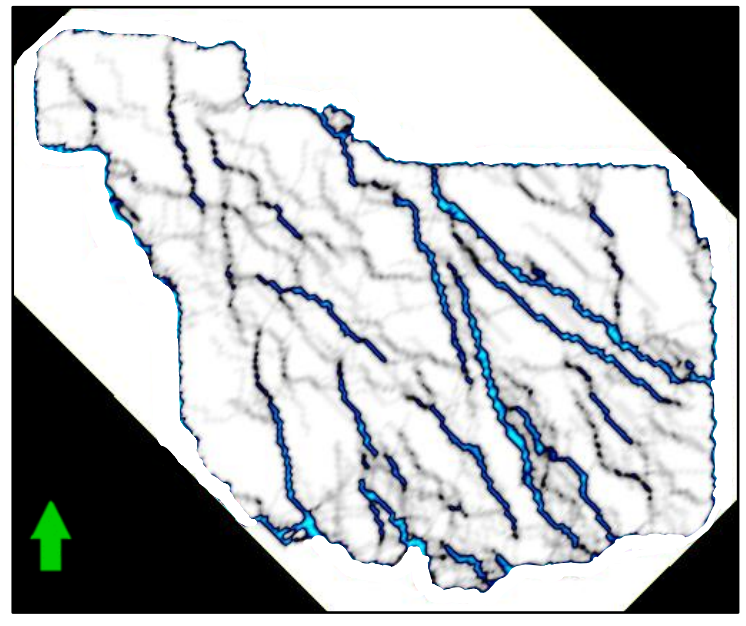

Figure 6: Ant-tracking example in Clearfield 


\subsubsection{Fracture and hydrocarbon correlation detection using Sweetness}

Sweetness is a volume attribute first described by Radovich and Oliveros (1998). It is another machine learning method that can be used to identify lithology, specifically thick, clean sandstone layers, hydrocarbon filled reservoirs, and/or to define channel fill (Hart, 2008). Sweetness is derived from the reflection strength or the instantaneous amplitude and instantaneous frequency, which varies by the type of lithology and/or hydrocarbon presence. This attribute can be used to compare and contrast the relationship between fractures and hydrocarbon filled areas. The question that needs to be answered is "does productivity correlate negatively with the presence of fractures in Clearfield reservoir?" This attribute allows us to investigate the relationship between sweetness and fractures, and the communication between those two aspects. Below is the equation of sweetness attribute:

$$
\text { Instantaneous sweetness }=\frac{\text { Instantaneous amplitude }}{\sqrt{\text { Instantaneous frequency }}}
$$

Sandstone for instance, may be a good reservoir rock as it usually has high porosity. Its high amplitude and low frequency would translate as a high sweetness value on the map. Therefore, it may be indicative of oil and gas filled sandstone reservoirs. The high acoustic impedance along the shale-sandstone boundary would also be a good indication. 


\subsubsection{Fracture Orientation using Dip Angel \& Azimuth and Histogram}

Maps of dip angle and azimuth show its variations over the study area and across the horizons. Dip angle is expected to be higher along faults and fracture boundaries and contrasting with the neighboring rock as it dips in a defined angle. The azimuth map will show the changes in its orientations. Further interpretation will be made based on any distinct pattern seen. Next, the histograms will be generated to show fracture distribution of both dip and azimuth statistically. The preferred fracture orientations and angles in the reservoir internally will be calculated and the changes across the horizons will be analyzed. 


\subsubsection{Geomechanical Analysis}

Understanding rock's elasticity is crucial to reducing risk of reservoir failure during drilling or hydraulic fracturing. Young's Modulus (YME) and Poisson's Ratio (PR) are two common measures used to estimate rock's elasticity, or brittleness. These geomechanical properties help us understand the strength of rocks. For example, rocks with high Young's Modulus are known to be hard or strong, thus having a high tendency to fracture. This valuable quality helps determine the amount of pressure needed during drilling or hydraulic fracturing. This paper will observe the interaction between fractures and the geomechanical strength of the rock by looking at the Young's Modulus (YME) and Poisson's Ratio (PR).

$$
\begin{gathered}
\text { Young's Modulus }=\frac{\text { Stress }}{\text { Strain }} \\
\text { Poisson's Ratio }=-\frac{\text { Lateral Strain }}{\text { Longitudinal Strain }}
\end{gathered}
$$

YME is also known as elastic modulus indicating the relationship between the longitudinal stress of rock and the longitudinal strain caused by that stress (Sarem and Riahi, 2020). PR is the ratio of lateral strain compared to the longitudinal strain (Warpinski, Branagan, and Wilmer, 1985). It measures the degree of deformation or changes done by the stress. High ratio indicates that the lateral strain is high, therefore the formation is mechanically plastic or weak. 
Although these parameters do not directly measure brittleness of rocks, low YME and high PR are shown to have low brittleness index $(\mathrm{BI})$ as shown in the figure below.

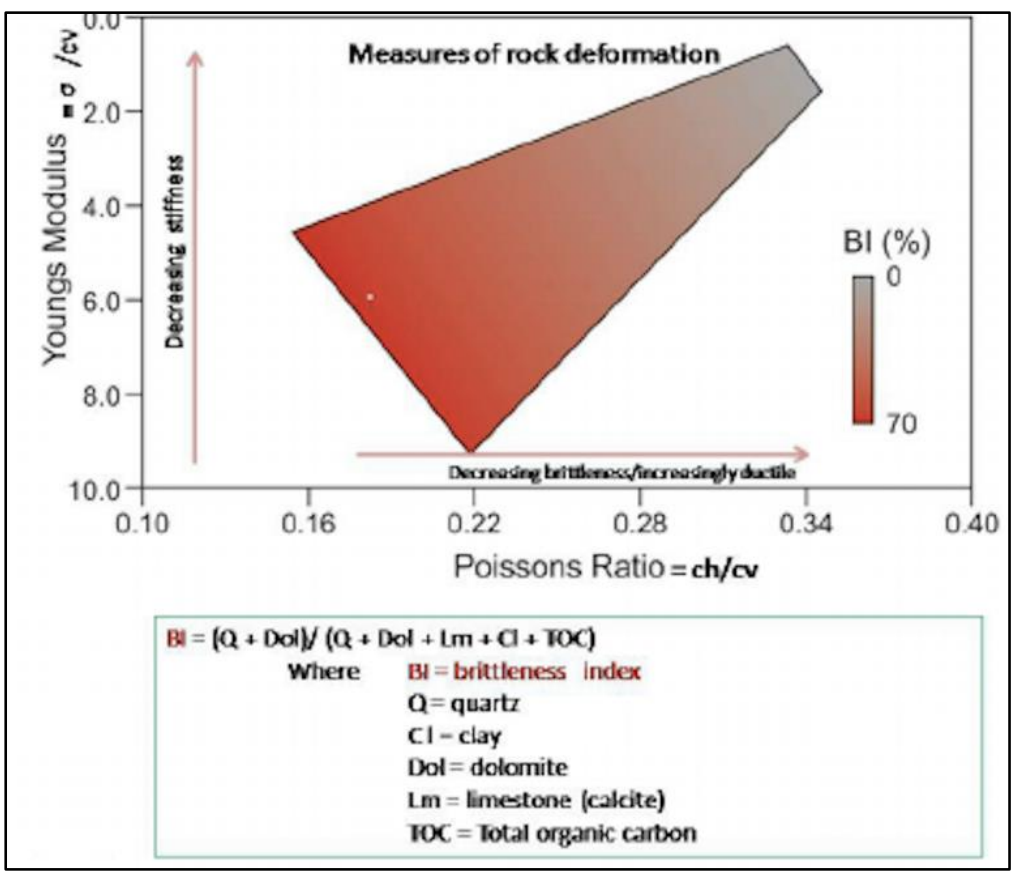

Figure 7: Graph of YME and PR compared to brittleness index (BI) and BI equation (Slatt, 2011)

Figure 7 above shows the measures of rock deformation by illustrating the relationship between YME and PR and the brittleness index $(\mathrm{BI})$ of rock. YME scale increases from top to bottom. High YME and low PR rock has high $\mathrm{BI}$, which indicates that the rock is more brittle. In other words, the rock is geomechanically fragile to stress and fractures easily, thus, less pressure is required during hydraulic fracturing. On the other hand, low YME and High PR rock has low BI making it more ductile and harder to break. Therefore, during hydraulic fracturing, more pressure is required to fracture this type of rocks. 
Table 1 below shows the relationship of YME and PR value and the rock elasticity.

\begin{tabular}{|c|c|c|}
\hline Property & Value & Indication \\
\hline \multirow[t]{2}{*}{$\begin{array}{r}\text { Young's modulus } \\
E\end{array}$} & Low & $\begin{array}{l}\text { Soft, flexible, and } \\
\text { resist brittleness }\end{array}$ \\
\hline & High & $\begin{array}{l}\text { Hard, Stiff, and } \\
\text { brittle rock }\end{array}$ \\
\hline \multirow{2}{*}{$\begin{array}{r}\text { Poisson's ratio (PR) } \\
\mu\end{array}$} & Low & Easy to fracture \\
\hline & High & Hard to fracture \\
\hline \multirow{2}{*}{$\frac{E}{P R}$ ratio $\frac{\text { Young's modulus }(E)}{\text { Poission's ratio }(\mu)}$} & High & Brittle and frackable \\
\hline & low & $\begin{array}{l}\text { Soft and resist to } \\
\text { fracture }\end{array}$ \\
\hline \multirow{2}{*}{$\begin{array}{l}\text { Fracture toughness } \\
\qquad K_{i c}\end{array}$} & Low & Brittle \\
\hline & High & Ductile \\
\hline
\end{tabular}

Table 1: Rock's elasticity versus YME and PR value (Khajah, 2020)

$\mathrm{Bl}$ is also calculated by taking into account the mineralogy and the total organic carbon (TOC) content. Quartz, dolomite, limestone, clay and TOC content are used in the equation to estimate BI (Jarvie et al.,2007 and Slatt, 2011):

$$
B I=\frac{\text { Quartz }+ \text { Dolomite }}{\text { Quartz }+ \text { Dolomite }+ \text { Limestone }+ \text { Clay }+ \text { TOC }}
$$

Although in most cases quartz and dolomite are thought to be more brittle than clay, the composition variations may change its brittleness. In this study, the rock's mineral composition is neglected to calculate the brittleness and focus only on the ratio of YME and PR. 
The YME measured in the laboratory have different values from the ones measured from seismic and well log data, and usually have lower values. They are known as static YME (measured in laboratory) and dynamic YME (calculated from well logs and seismic waves). According to Valim, 2013, the variation may be due to the fluid saturation level difference between the two settings as the sound wave velocity increases in the rock saturated with fluid. 


\subsection{Results}

\subsection{Variance and Maximum Curvature}

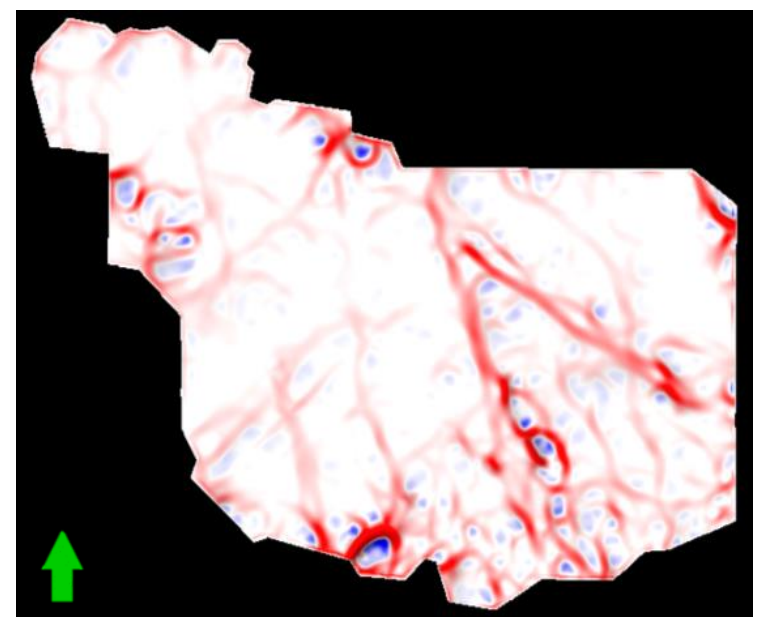

Figure 9: Curvature attribute on Tully Limestone

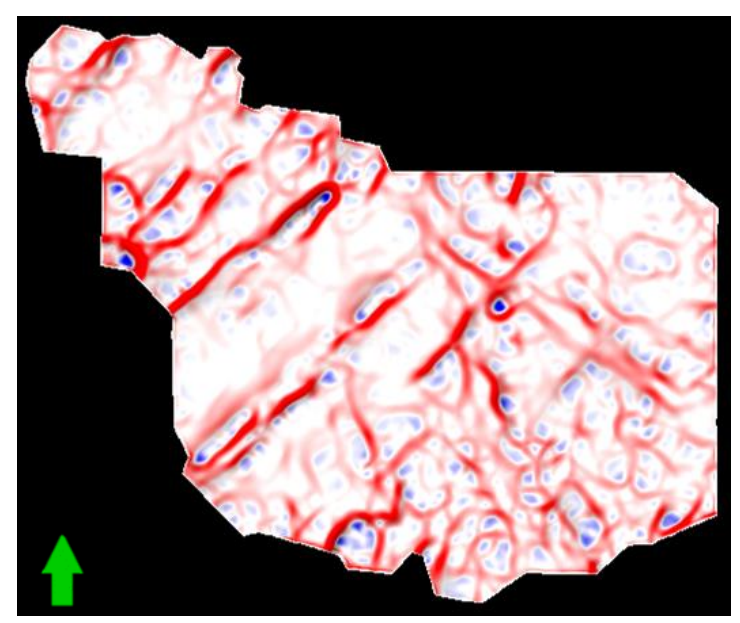

Figure 11: Curvature attribute on Onondaga Limestone

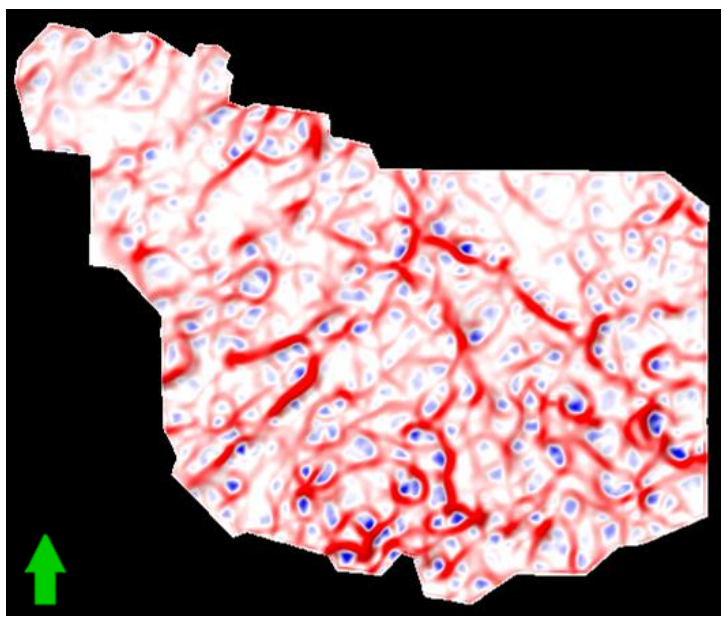

Figure 8: Curvature attribute on Marcellus Shale

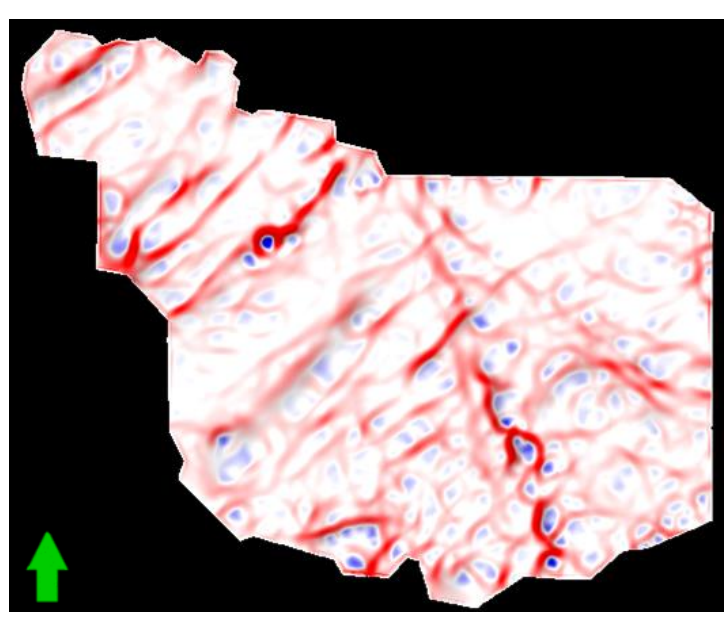

Figure 10: Curvature attribute on top Salina Salt 

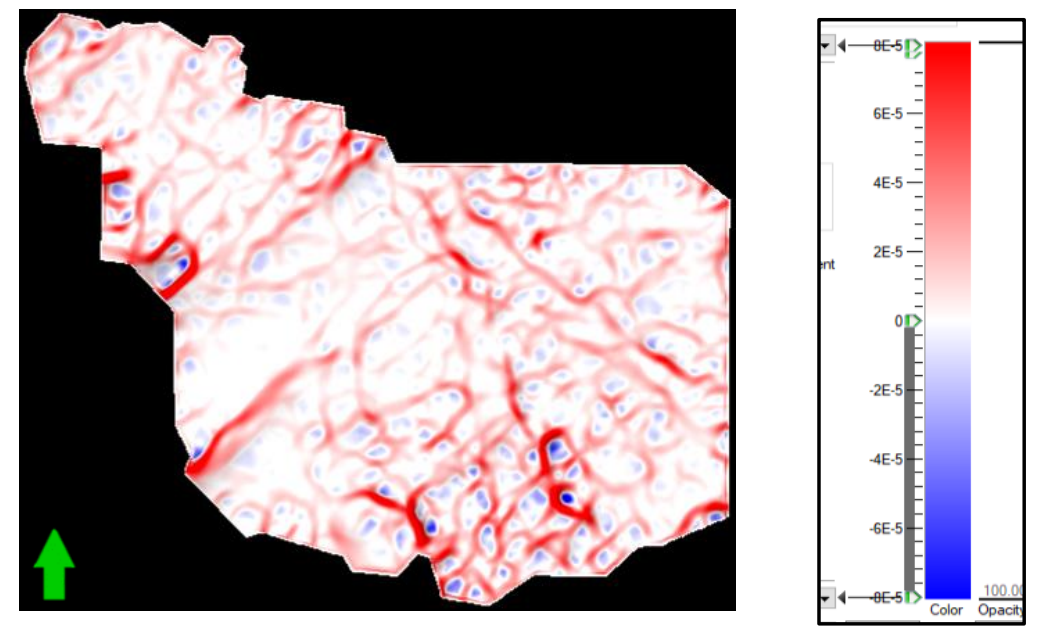

Figure 12: Curvature attribute on base Salina Salt

Figures 8-12 above show the curvature attribute maps for Tully Limestone, Marcellus Shale, Onondaga Limestone, and top and base of Salina Salt respectively. The red color indicates positive curvature (anticline), while blue indicates negative curvature (syncline). White color on the maps indicates that there is no curvature or that the area rea relatively flat.

The Tully Limestone (Figure 8), deposited during the Middle Devonian has majority of northwest trending lineaments with minor northeast trending lineaments. The northeast trending lineaments can be seen on the older deposits namely the Onondaga Limestone (Figure10) and diminish towards the younger deposits such as Tully Limestone. Meanwhile, the Marcellus Shale layer (Figure 9) is heavily fractured, and the scale are also shorter compared with other horizons. On Marcellus Shale horizon, there are some small blue circle-shaped features that are dominant in the southwest region. 
These features could be small bowls or depressions as a result of heavily fractured rock that may complicate the prediction of fluid flow.

The top Salina Salt (Figure 11), deposited in the Silurian has a majority of northeast trending lineaments and fractures, with minor northwest trending lineaments. The top, which is the detachment horizon, is heavily deformed than the base Salina Salt (Figure 12).

The difference in the fracture trends suggests that the northeast trending lineaments were initiated during the Silurian and started to diminish towards the younger Tully Limestone in the Middle Devonian. The northwest trending lineaments, on the other hand, are more intense in the younger rock. It implies that these lineaments are relatively young and only beginning to propagate in the younger rocks. 


\subsection{Ant-Tracking}

Ant-tracking attribute predicts potential hydrocarbon migration paths in a reservoir by detecting fracture swarms. Figures 14-18 show the Ant-Tracking maps on the horizons. The parameters are adjusted to track only high angle dip of more than $60^{\circ}$ using the stereonet function. The preferred angles are the unshaded area on the stereonet (Figure 13) with azimuth in all directions.

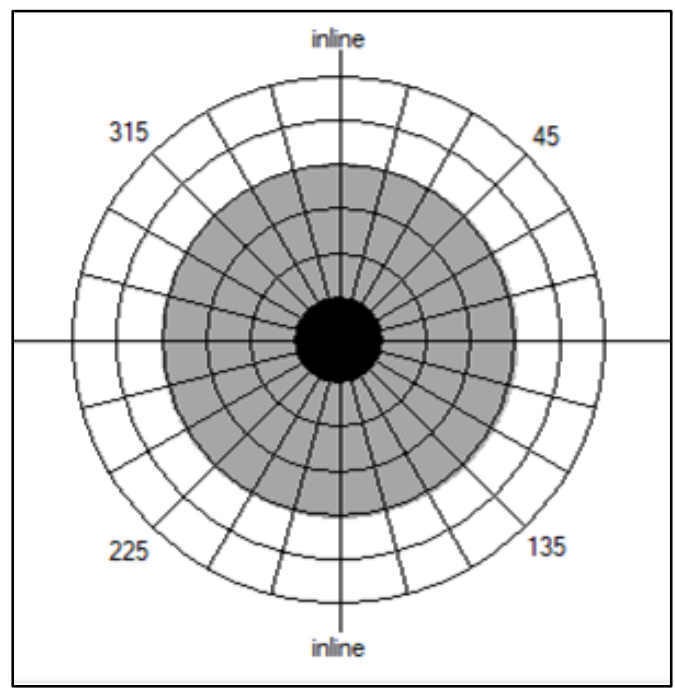

Figure 13: Stereonet showing the preferred dip angle of $>60^{\circ}$ 


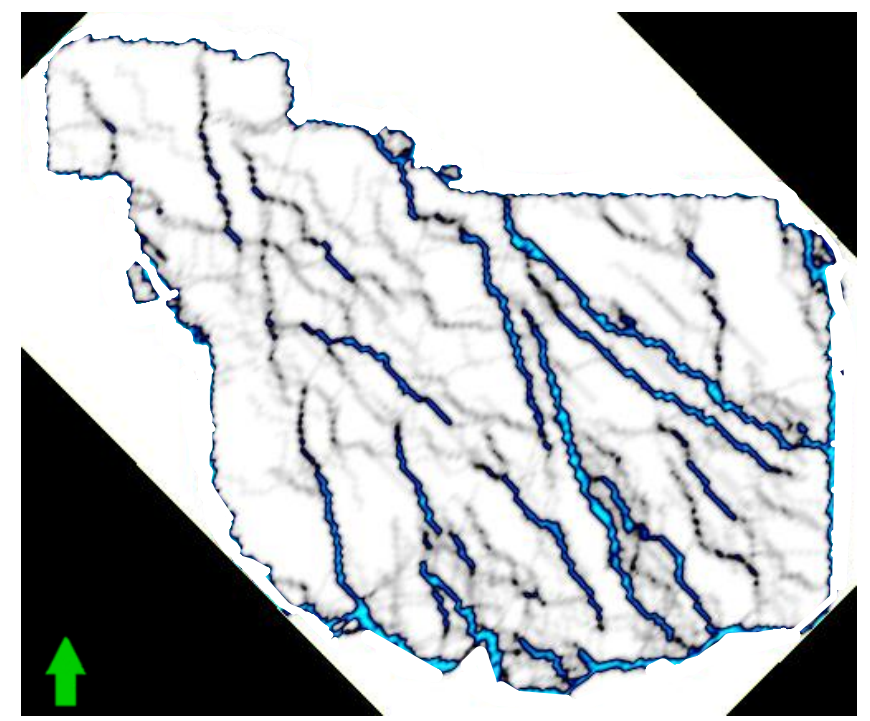

Figure 14: Ant-tracking on Tully Limestone

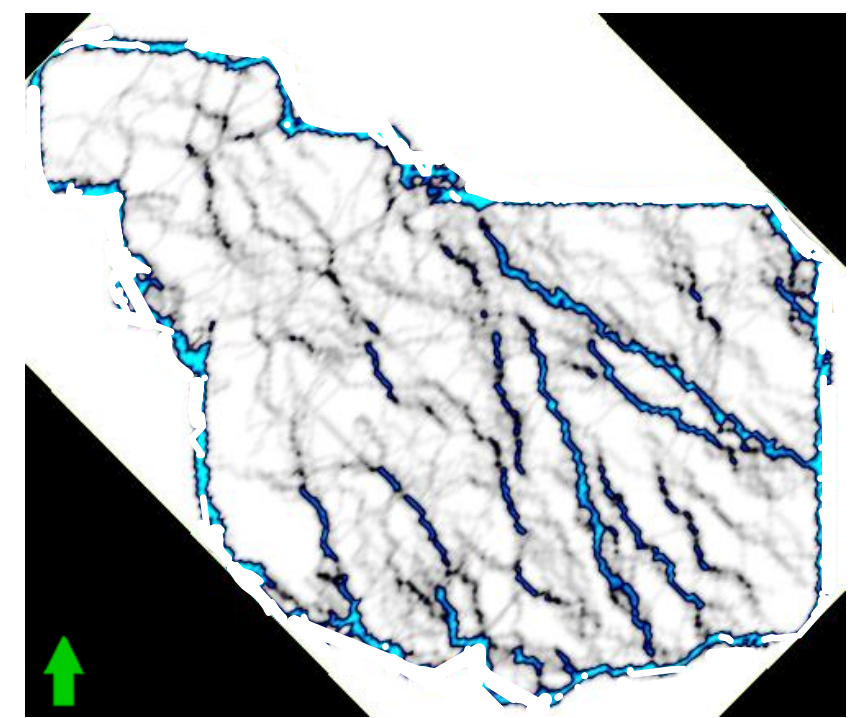

Figure 15: Ant-tracking on Marcellus Shale

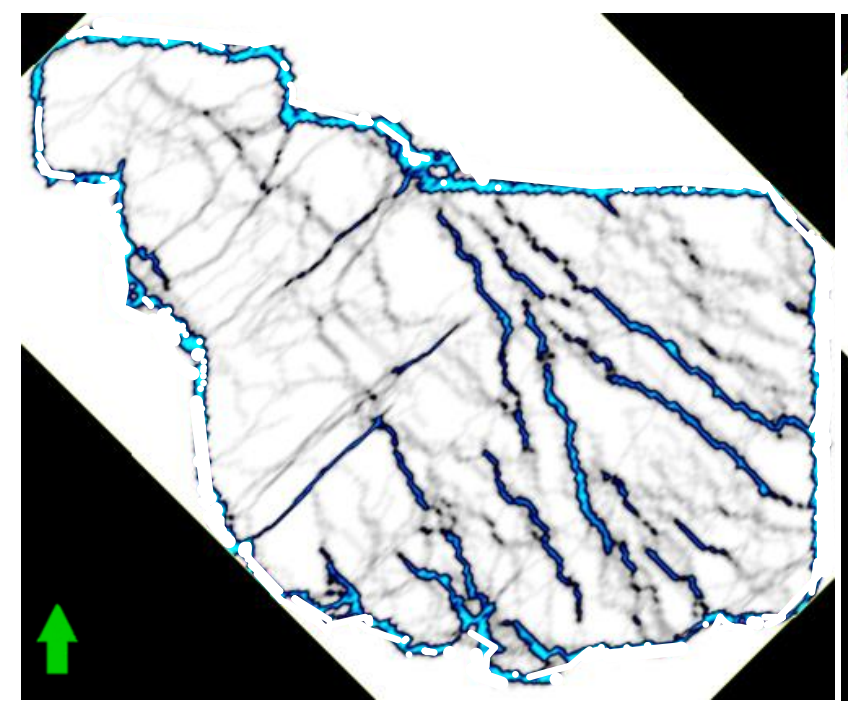

Figure 17: Ant-tracking on Onondaga Limestone

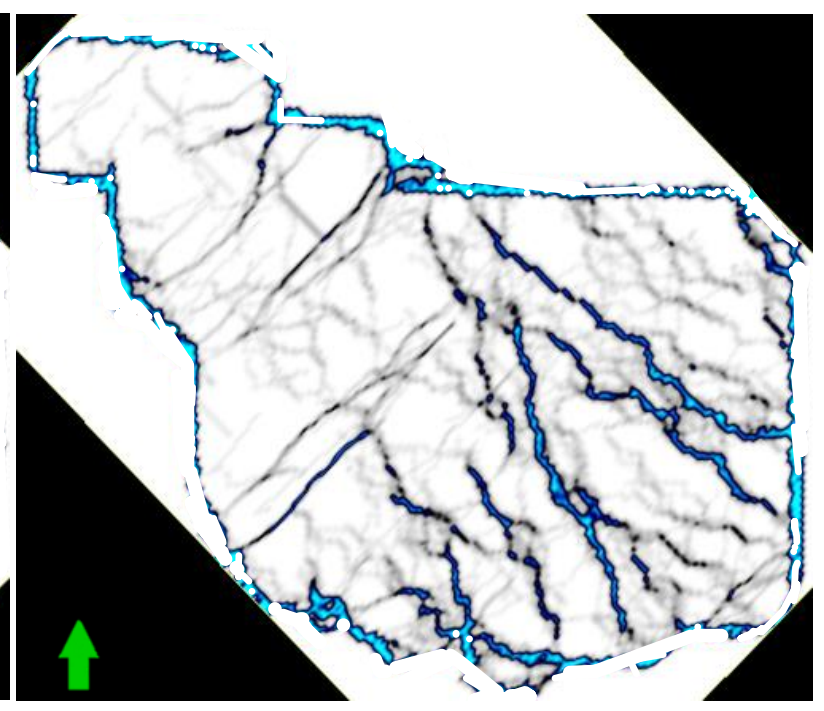

Figure 16: Ant-tracking on top Salina Salt 


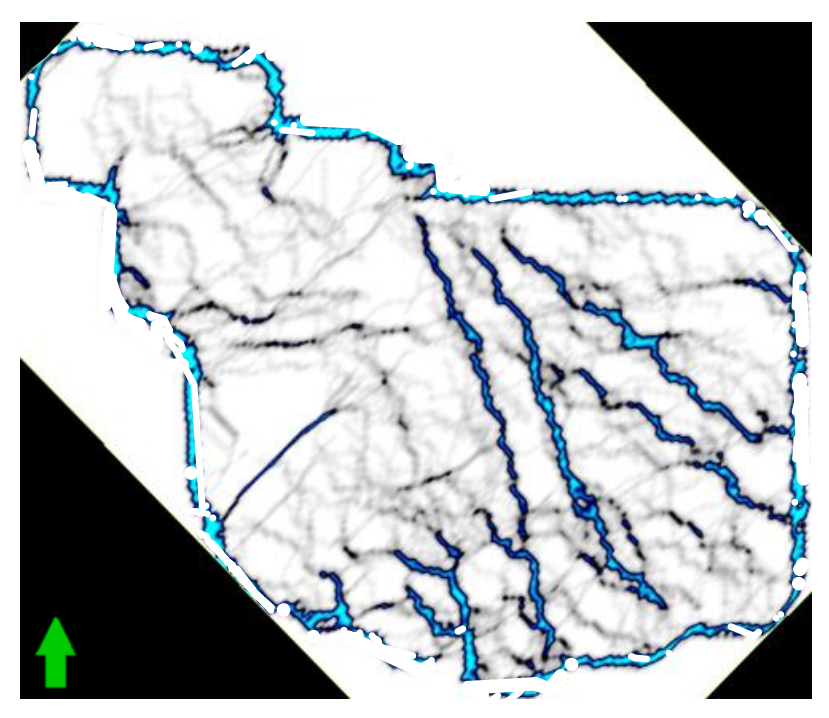

Figure 18: Ant-tracking on base Salina Salt 
Figure 14 to 18 show the ant-tracking maps of all the rock horizons with the preferred dip angle of more than $60^{\circ}$ with an 'aggressive' tracking pattern. The blue color denotes the 'ant-track' of spatially connected faults.

Although variance attributes can be used to delineate fractures, ant-tracking is believed to be a better attribute to evaluate both conventional and unconventional reservoirs. On top of tracing fractures, it also traces the fracture connectivity spatially and temporally. As seen from the maps above (Figures 14-18), there are two predominant northwest trending lineaments of a high angle that run across all the horizons. These almost vertical faults are transverse faults and are crucial in dictating the hydrocarbon flow. They may contribute to the low hydrocarbon productivity in this unconventional reservoir by allowing hydrocarbon to seep upward.

The youngest rock, Tully Limestone (Figure 14), has few minor northwest fractures connectivity on the western side of the region which are not prominent on other horizons. These fractures are shallow and relatively young faults. Figures 16-18 show some minor northeast trending faults on the western side of the map which cannot be seen on the younger rocks. These faults are older structures, generated by the westward compressional force. The detachment horizon, Salina Salt is mechanically weak and causes the overlying rocks to be more susceptible to the compressional stresses (Robert, 2010), thus affecting its structures. 

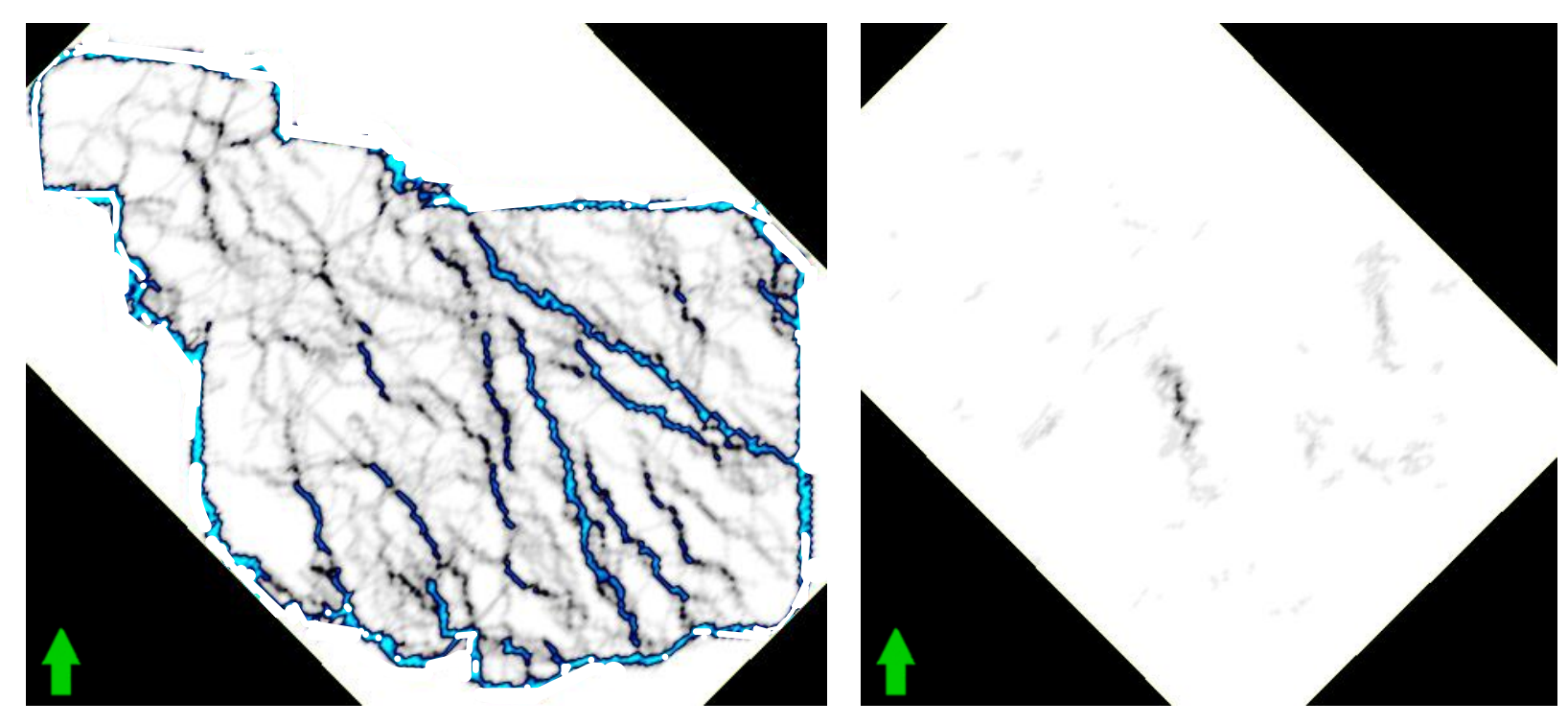

Figure 19: Ant-tracking on Marcellus with $60^{\circ}$ dip (left) compared with $<30^{\circ}$ dip (right)

Figure 19 above are ant-tracking maps on Marcellus Shale but with different preferred dip angles chosen. Figure 19 (left) used $60^{\circ}$ dip angle while figure 19 (right) used $30^{\circ}$ angle and less to 'ant-track' fracture connectivity. This shows that the majority of faults and fractures here are of high dipping angles. Based on the maximum curvature map (Figure 9) generated earlier, the Marcellus Shale is shown to be fractured heavily all across the map. However, the ant-tracking map (Figure 15) shows that only those of high angle fractures have high connectivity, while low angle fractures have low connectivity and are not spatially connected. By considering only the fracture connectivity, this unconventional reservoir may have had a good natural permeability that would allow hydrocarbon flow during drilling. The top rock layer, the Tully Limestone (Figure 14) has also shown the same high angle fractures connectivity. These fractures are communicating across the reservoir temporally, which has caused 
the hydrocarbon from the source rock to migrate to the surface via Tully Limestone that otherwise would have been a good cap rock to trap the hydrocarbon. This explains the fact that this region, although having a high-quality source rock, fails to produce the expected amount of hydrocarbon. 


\subsection{Sweetness Attribute}

Sweetness attribute is derived from dividing the reflection strength, which has the same unit as amplitude, by the square root of instantaneous frequency, with unit of hertz (Hart, 2008). Referring to the sweetness expression, a high sweetness value is associated with high amplitude and low frequency and may be interpreted as hydrocarbon-bearing sand units (Emujakporue and Enyenihi, 2020). Shale on the other hand, is characterized by low amplitude and high frequency thus resulting in low sweetness. For unconventional reservoirs, hydrocarbon-bearing sand units are common drilling targets. In previous studies, the sweetness attribute was used to identify sweet spots which are prone to hydrocarbons in which high sweetness values are possible indications of oil and gas (Radovich and Oliveros, 1998;Hart, 2008).

Sweetness attribute is measured as relative value. The scale of the maps (Figure 20 and 21) has been adjusted; therefore, these values are relative. Warmer colors indicate high sweetness, while cooler colors indicate low sweetness. Although these values are arbitrary, it is still beneficial for faults and fractures detection and interpretation in unconventional reservoirs. 


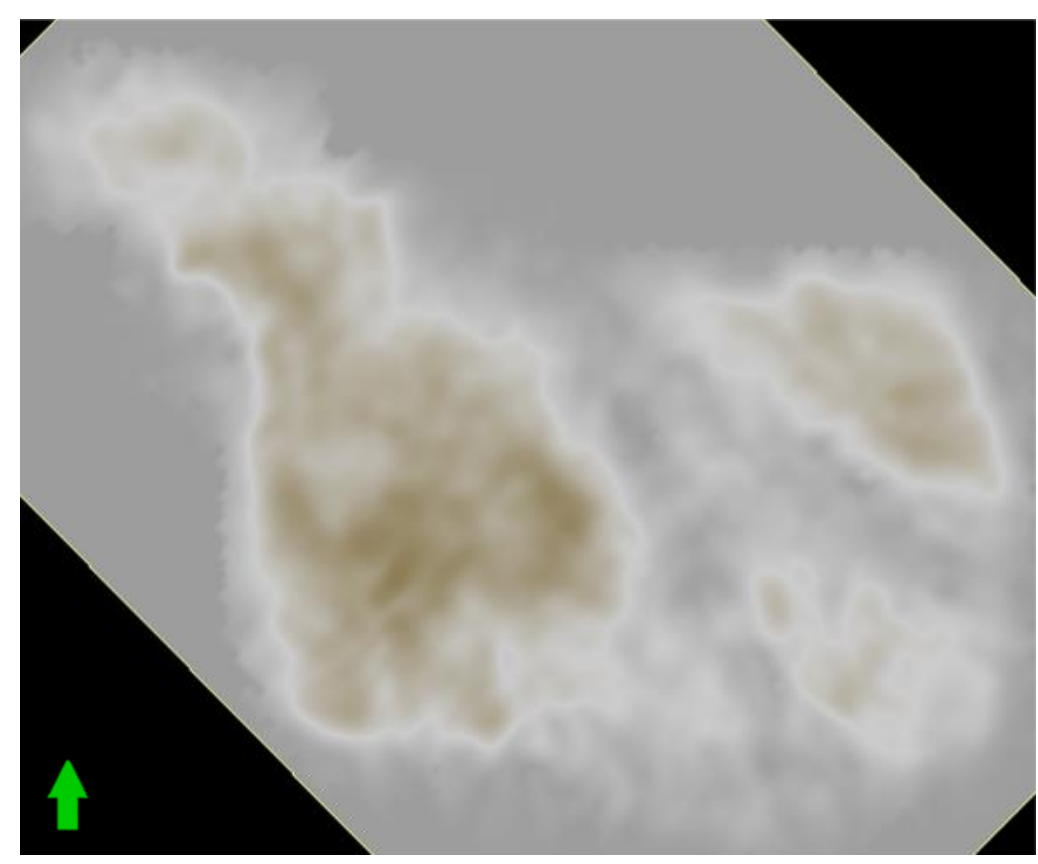

Figure 20: Sweetness map before scale adjustment

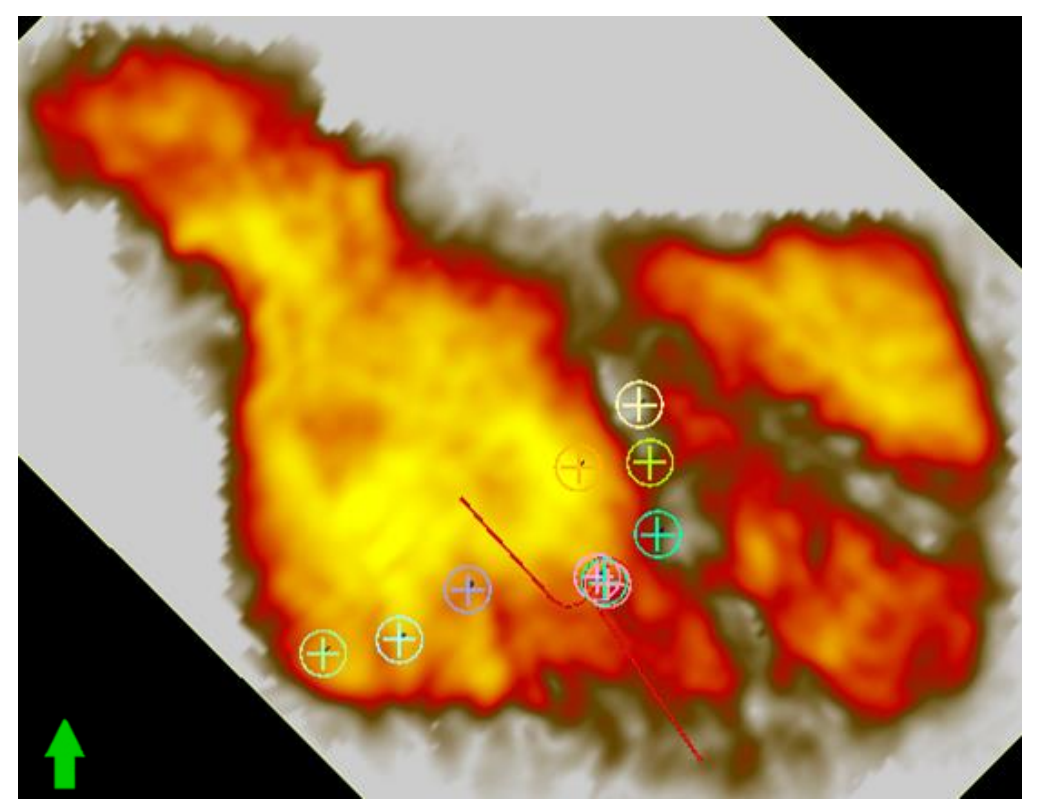

Figure 21: Sweetness map after scale adjustment 
Figure 20 shows the sweetness map before the scale adjustment and figure 21 shows the sweetness map in the study area after the scale has been adjusted. It suggests low sweetness value along the north-west trending faults. Besides delineating hydrocarbon-bearing sand units, this attribute is also useful in indicating faults. Faults translate to low amplitude in seismic imaging, and have lower travel time or velocity, thus having low amplitude-frequency ratio. This results in low sweetness values along the intense faults. Therefore, big intense faults can also be considered as non-sweet spots for drilling. 


\subsection{Dip Angle Map and Histogram}

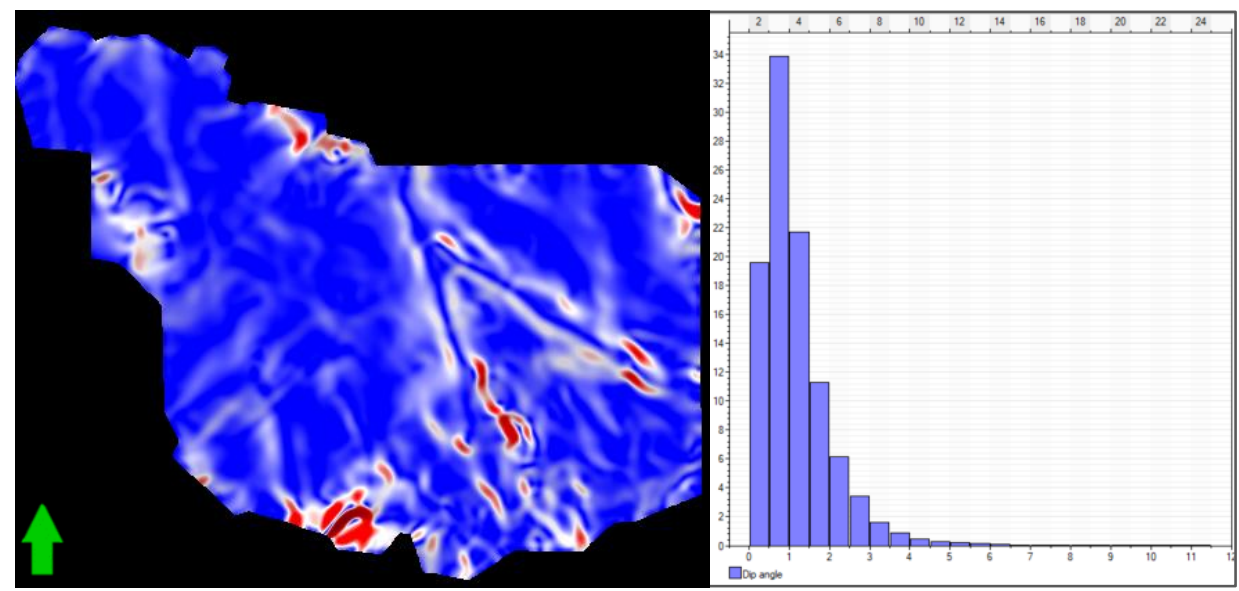

Figure 22: Dip angle map and histogram of Tully Limestone

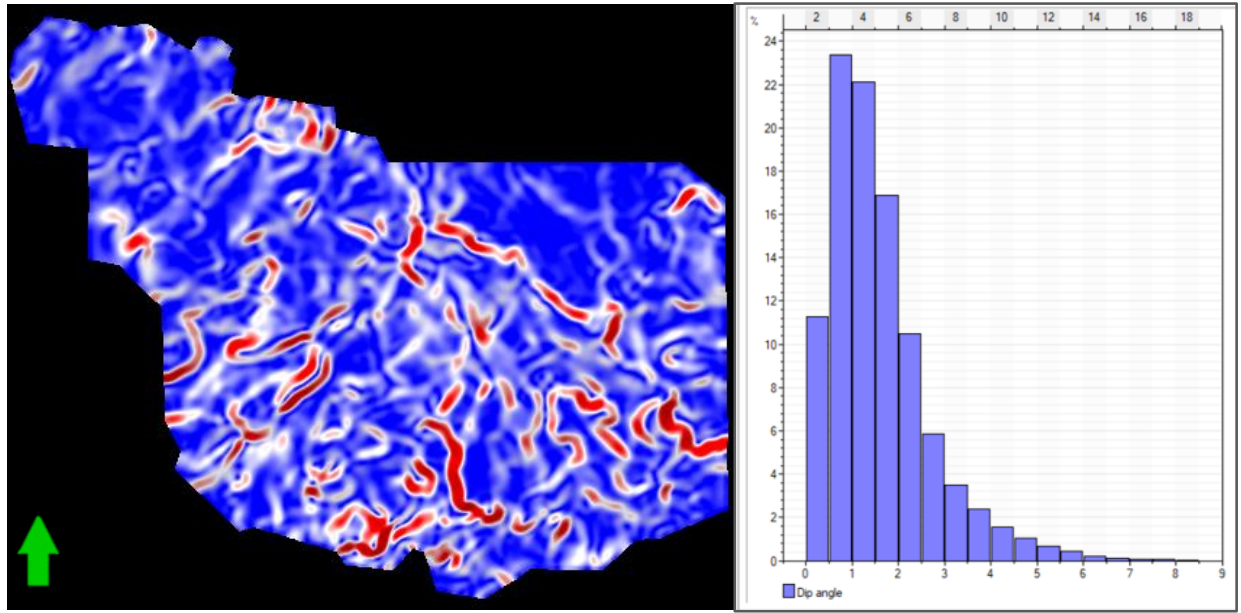

Figure 23 Dip angle map and histogram of Marcellus Shale
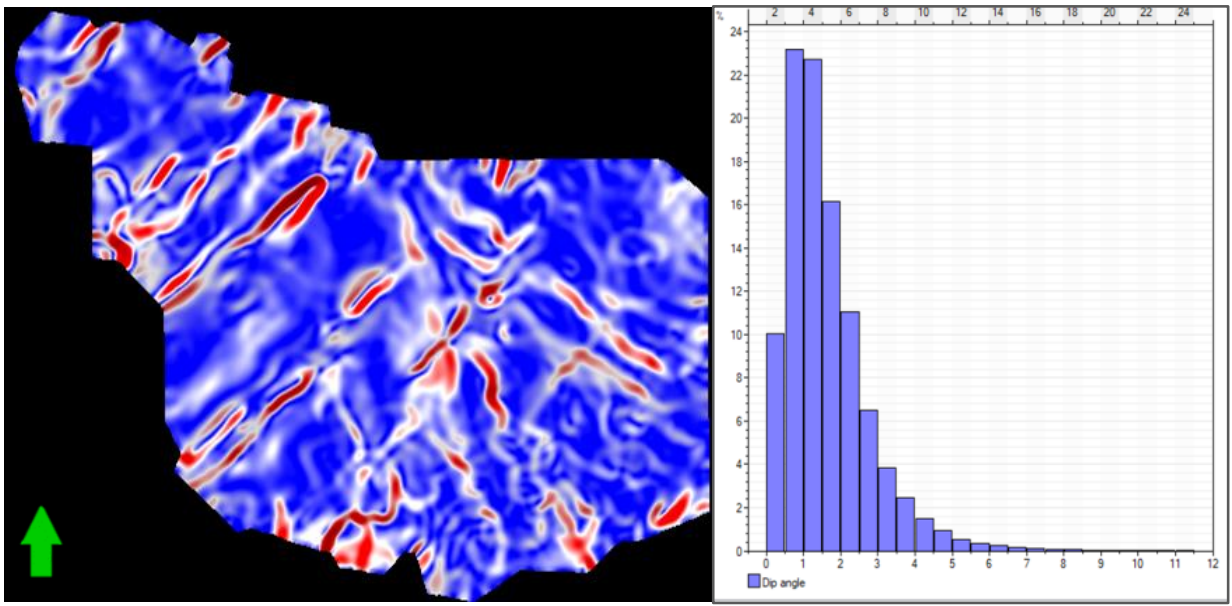

Figure 24: Dip angle map and histogram of Onondaga Limestone 

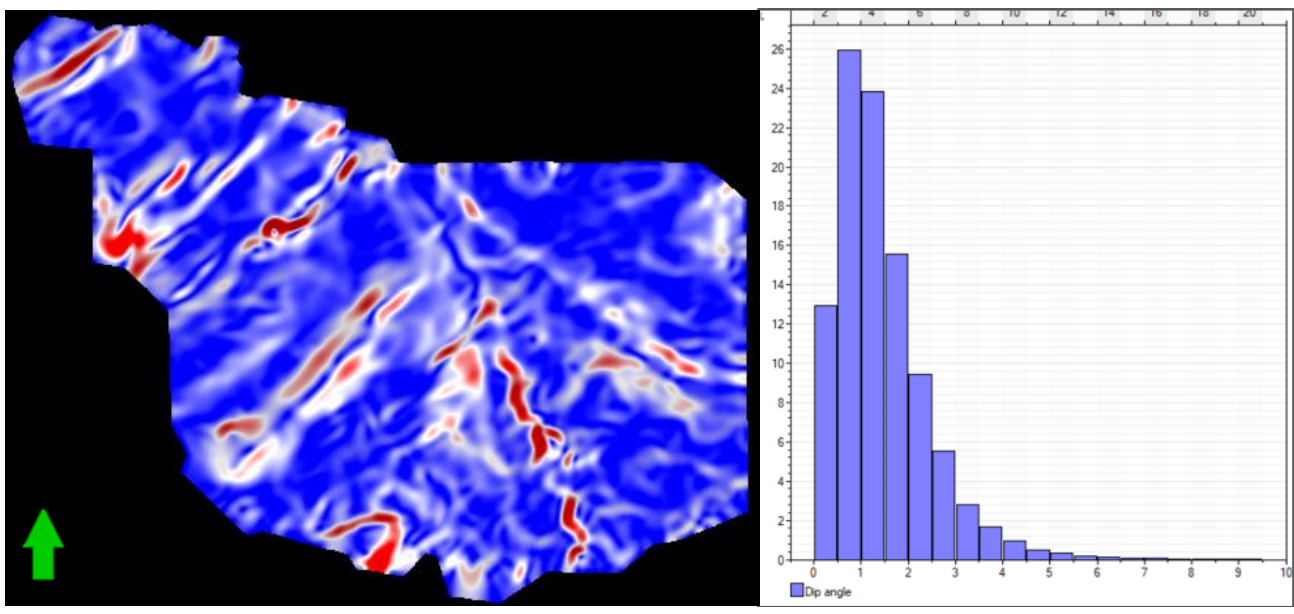

Figure 26: Dip angle map and histogram of top Salina Salt
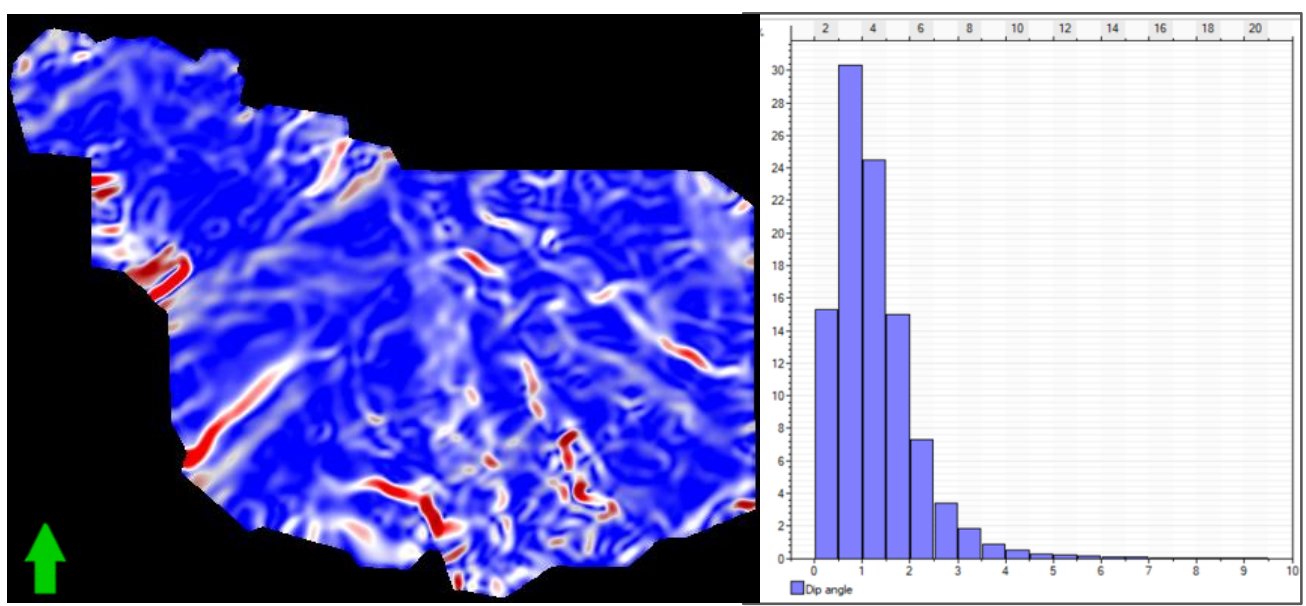

Figure 25: Dip angle map and histogram of base Salina Salt

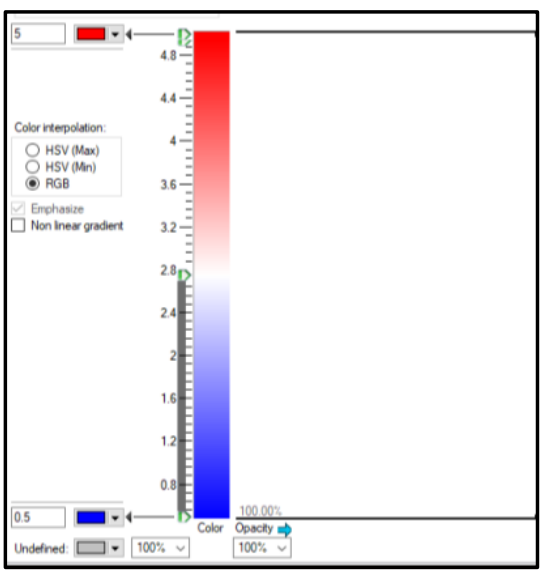


Figures 22-26 above show the dip angle maps and dip distributions of each horizon. Red color indicates a high dip angle and blue indicates a low dip angle. These maps agree with the curvature maps as they highlight the dipping rock along the faults. The bright red color outlining the faults shows high intensity of dipping rock due to the disruption by the discontinuities. The histogram accompanied by the maps shows the distribution of the angles in a more quantitative way to help understanding the map better.

Tully Limestone (Figure 22) has the least dipping rock abundance, and the histogram has narrow distribution. This may be due to the fact that limestone is generally stiffer, thus having less fractured rock. In comparison, Marcellus Shale layer (Figure 23) has abundant smaller scale fractures with higher dip angle. The rock layer is heavily disrupted and has wider distribution on the histogram. Compared with the rest of the rock layer, Marcellus Shale tend to dip in a non-specific orientation, which will be proven later using the dip azimuth attribute. The majority of the fractures do not fall in a straight line which may be an indicative of an isotropic rock.

Onondaga Limestone (Figure 24), a rock layer that underlies Marcellus Shale, also has high dipping rock distribution on the histogram. The dip angles of this rock layer are also on the higher side of the scale. From the map generated, it is visible that the rock layer is heavily fractured with straight and undeviating fractures.

Salina Salt (Figures $25 \& 26$ ) is geomechanically weak and has high resistance to stress. In other words, this formation is harder to fracture as it behaves more plastically. This fact is supported by the map and histogram generated. It has lower 
fracture abundance compared with other rock layers except Tully. The dip angle is also low comparatively. However, the top layer has higher dipping rock abundance since it is the detachment horizon and serves as a base for the overlying rock to deform. 


\subsection{Dip Azimuth Map and Histogram}

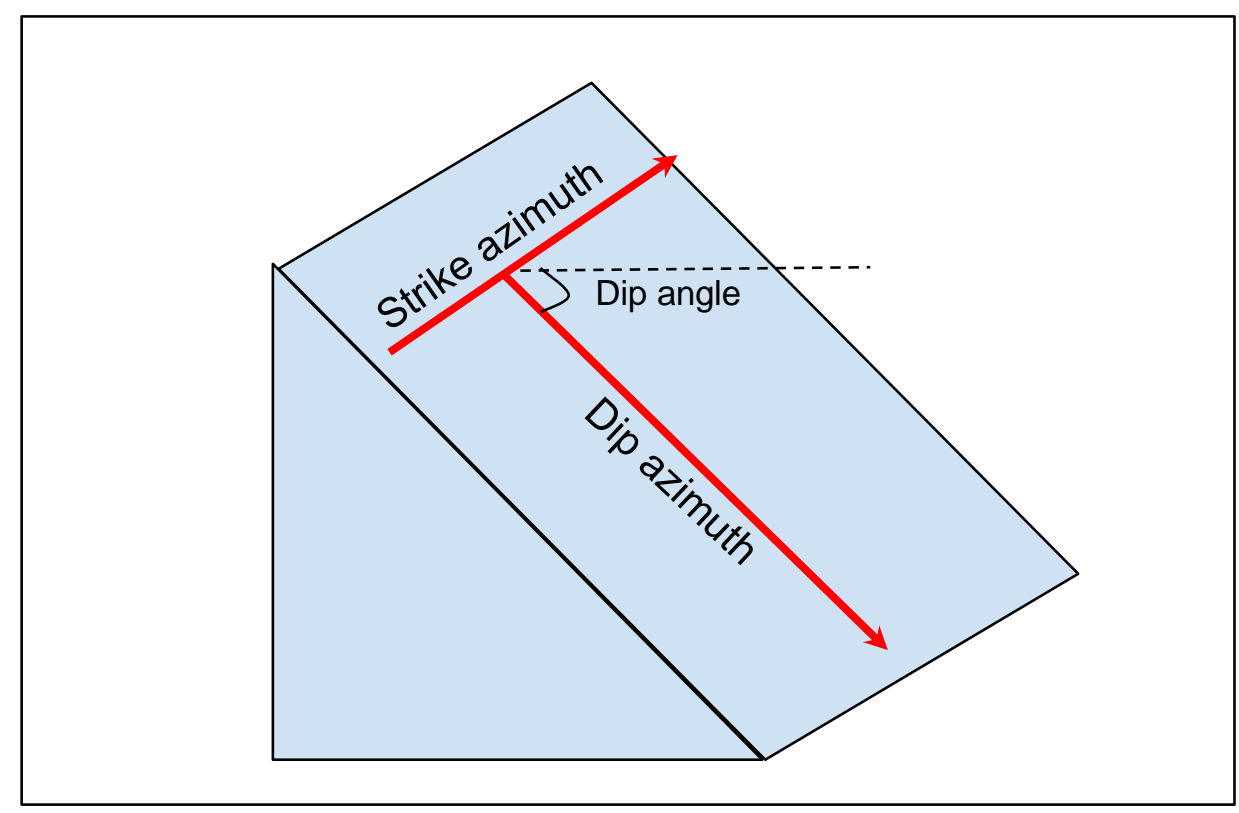

Figure 27: Dip azimuth, dip angle and strike diagram

Figure 27 above illustrates the dip azimuth, dip angle, and strike azimuth/plane. The strike azimuth is the direction of the rock plane. The dip azimuth is the direction of the dipping side of the rock, and it is always perpendicular to the strike plane or the fault plane. The dip angle is a measure of how tilted the rock is from a horizontal plane. The maps and histograms of dip azimuth are generated (Figures 28-32) to show the dip azimuth of the rock and its distribution across the layers. 


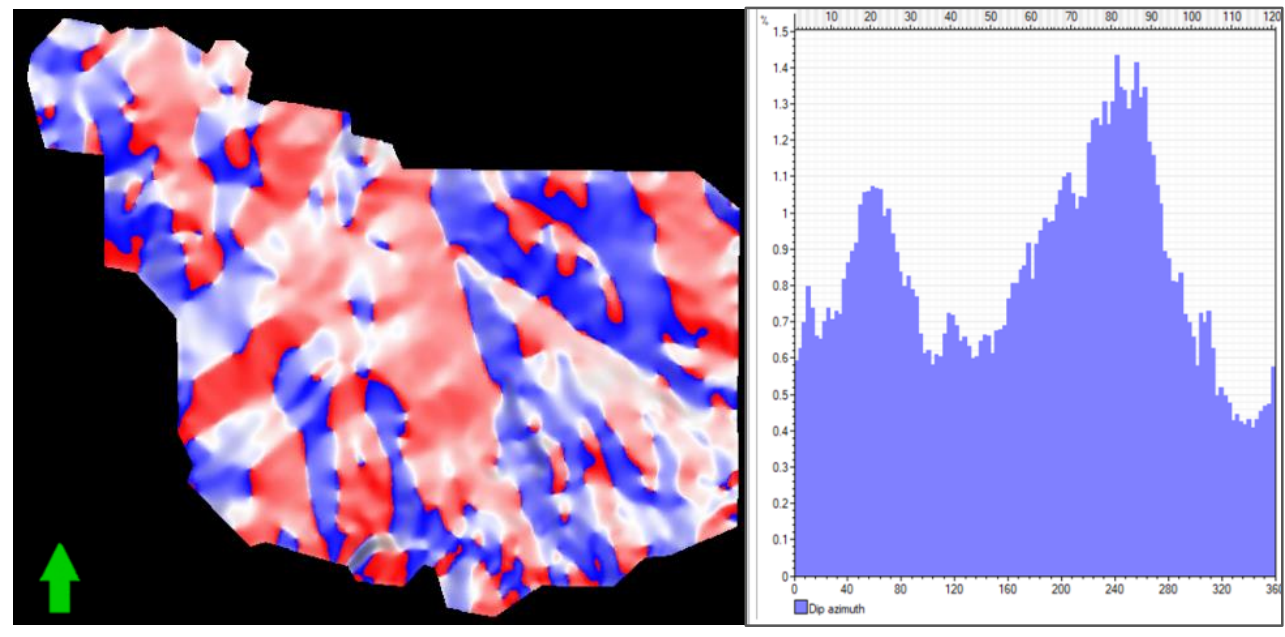

Figure 28: Dip azimuth map and distribution of Tully Limestone
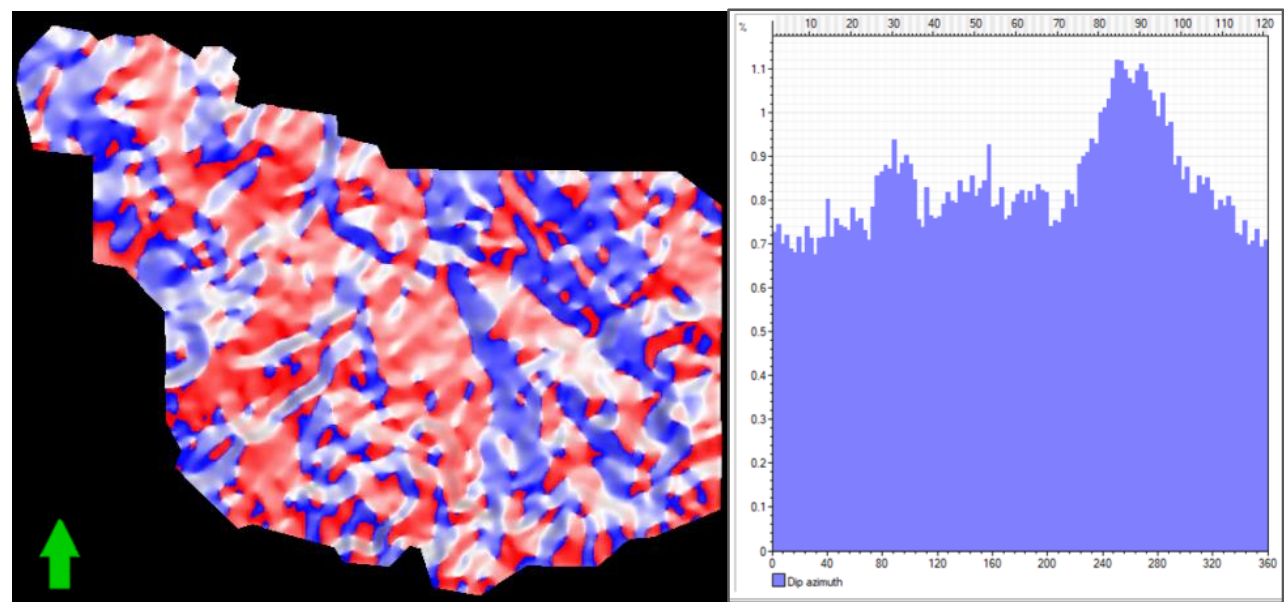

Figure 29: Dip azimuth map and distribution of Marcellus Shale

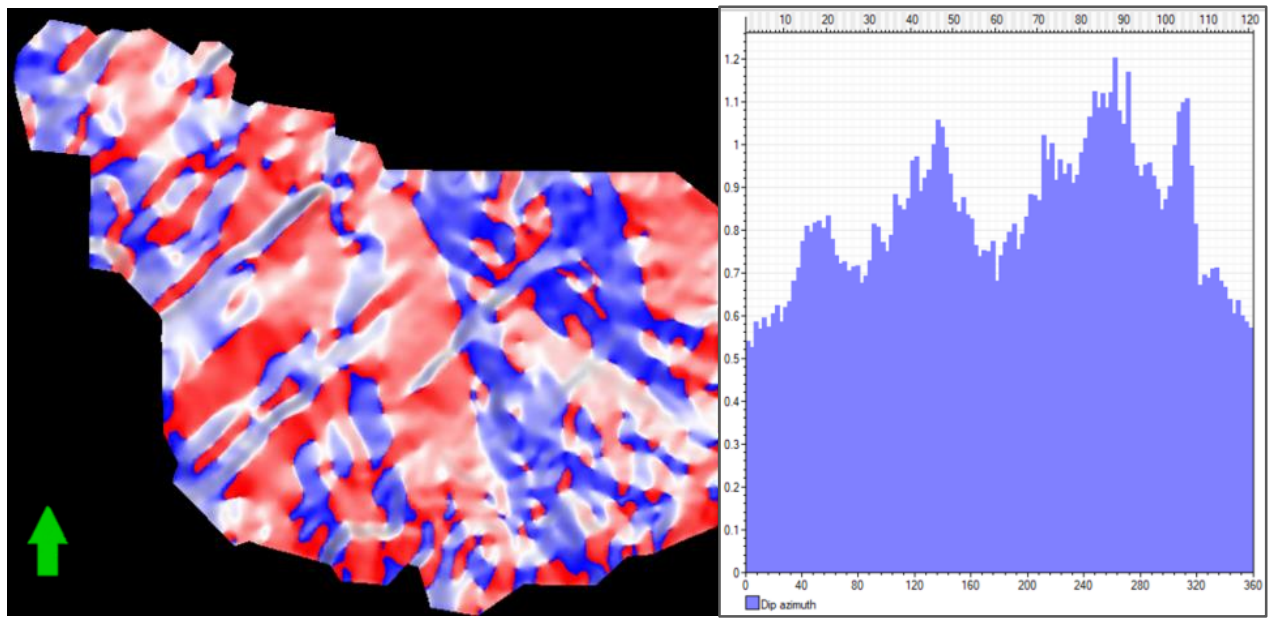

Figure 30: Dip azimuth map and distribution of Onondaga Limestone 


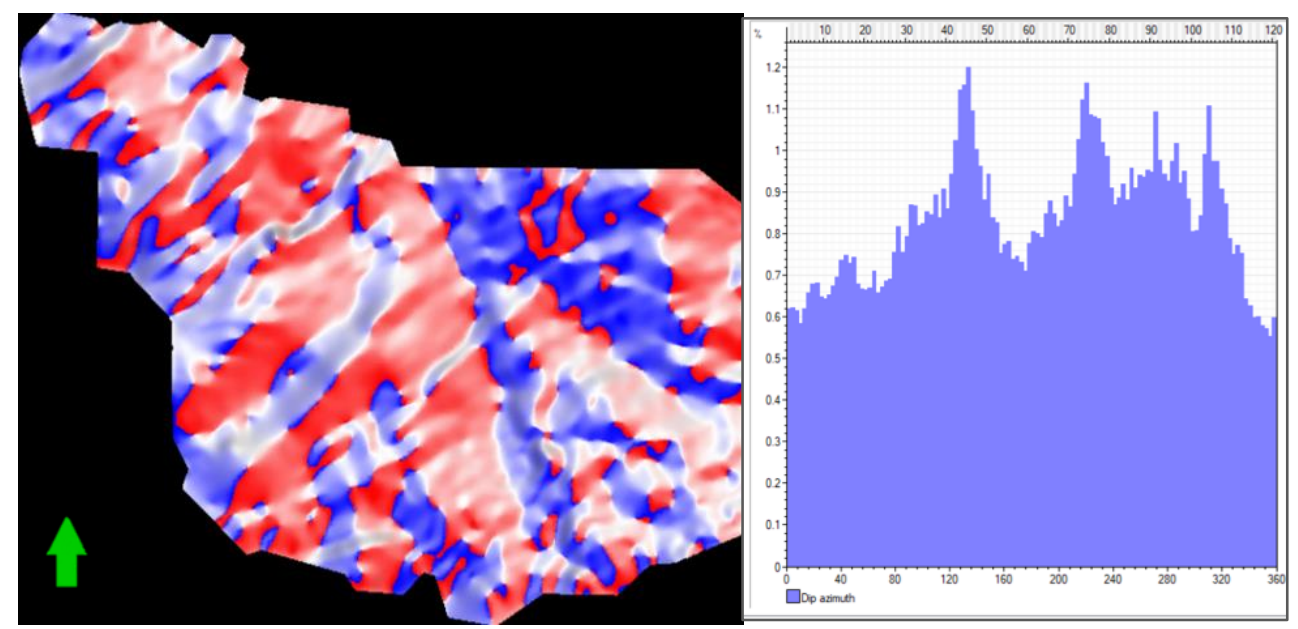

Figure 31: Dip azimuth map and distribution of top Salina Salt

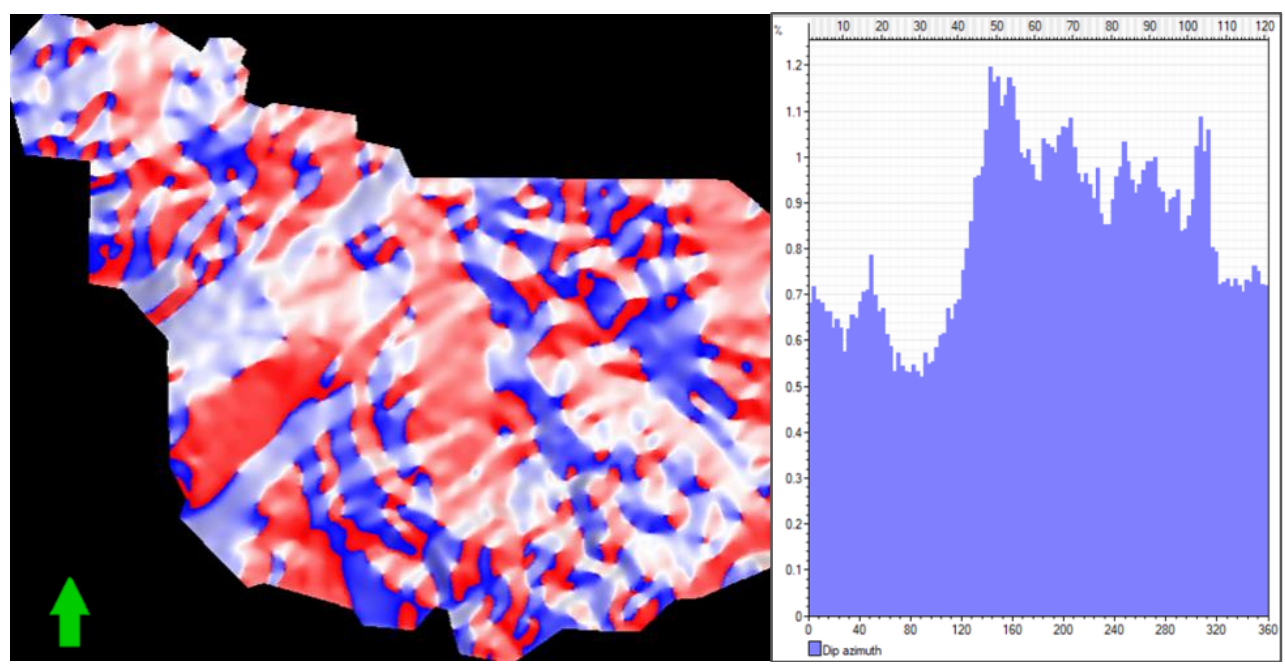

Figure 32: Dip azimuth map and distribution of base Salina Salt

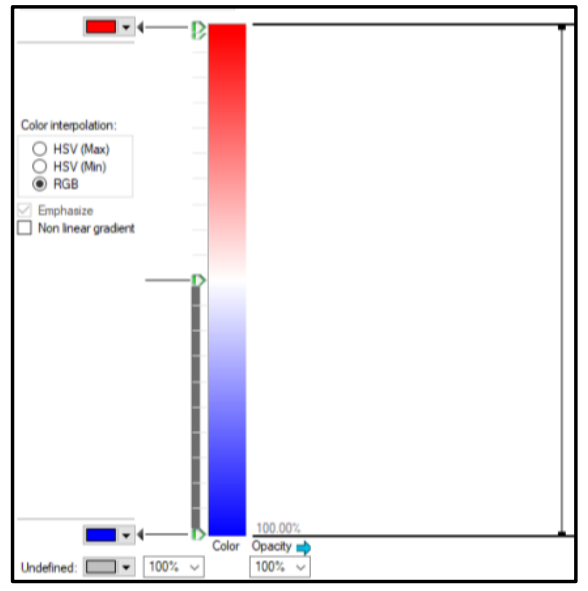


The blue color indicates NE-SW while red indicates NW-SE azimuth direction respectively. The histogram of Tully Limestone (Figure 28) shows that it has 2 preferred dip azimuth of $40^{\circ}-80^{\circ}$ and $200^{\circ}-280^{\circ}$ which is in the NE-SW direction. This data agrees with the fact that the major fault on Tully Limestone rock layer is the northwest trending, therefore having the rock dipping in the perpendicular direction. There is minor dip azimuth of NW-SE direction, but subtle. We can conclude that the northwest trending faults are the predominant faults on Tully Limestone.

Marcellus Shale has a homogenous dip azimuth distribution than Tully Limestone. The are no preferred dip azimuth on this horizon. Based on the histogram, the Marcellus Shale (Figure 29) has the highest fracture abundance and uniform distribution compared with the other horizons. This means that this layer has numerous smaller scale fractures with dip azimuth of mostly $240^{\circ}-270^{\circ}$ and $80^{\circ}-90^{\circ}$, which is in the NE-SW orientation.

The older rock, Onondaga Limestone that underlies the Marcellus Shale has a different preferred dip azimuth that peaked at $120^{\circ}-140^{\circ}$ and $260^{\circ}-290^{\circ}$, which is in the NW-SE orientation. This means that the faults are in northeast direction. This observation is consistent with the observation from the curvature maps that concludes northeast trending reverse faults are more prominent on this layer and diminishes towards the younger rock layers such as Marcellus Shale and Tully Limestone. 
The top Salina Salt (Figure 31) has the majority of rock dipping towards the southwest. The dip azimuth peak at $140^{\circ}, 220^{\circ}, 280^{\circ}$ and $300^{\circ}$ as seen on the histogram. The base Salina Salt has high azimuth distribution between $120^{\circ}-320^{\circ}$, which also in the same southwest direction. Ideally, the dip azimuth should be symmetrical since the rock along faults dip in the opposite direction. This is not the case for Salina Salt. The layer has asymmetrical rock dip azimuth and lean heavily towards southwest but not northeast. This indicates that the salt reacts differently when being compressed unlike shale, limestone or sandstone. 


\subsection{Geomechanical Analysis}

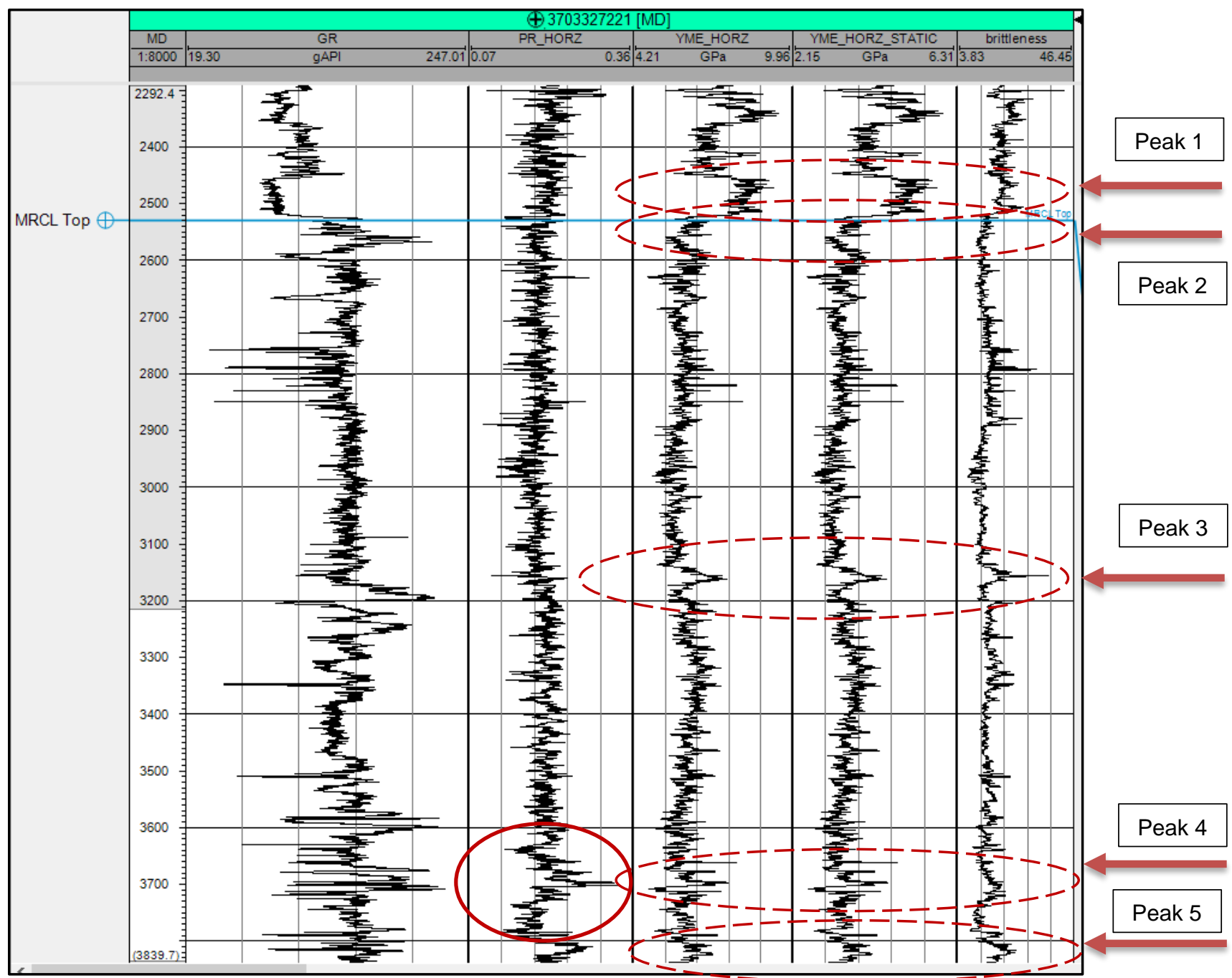

Figure 33: The well log data of the horizontal well \#3703327̄221

Figure 33 shows well log data of the Poisson's Ratio (PR_HORZ), dynamic horizontal Young's Modulus (YME_HORZ), static horizontal Young's Modulus (YME_HORZ_STATIC), and the brittleness of a horizontal well in Clearfield, respectively. The unit of measured depth (MD) is in meters and the Marcellus Shale top is marked with the blue line at the depth of about $2530 \mathrm{~m}$. The log data beyond the blue 
mark are collected horizontally across the Marcellus Shale horizon, therefore the 'depth' represents the horizontal distance.

The static YME is derived from the core sample while the dynamic YME is derived from the sonic log measurement. The static YME is typically lower in magnitude than the dynamic since the measurements are not taken on site directly. However, the changes and fluctuations in the reading are consistent. These geomechanical properties of the reservoir give us some understanding on the possible impact of fracking on the reservoir

The rightmost column is the brittleness log generated by calculating the ratio of YME and PR. It is a straightforward way to measure the rock brittleness by allowing us to see the changes in rock brittleness across Marcellus Shale spatially. High YME and low PR are associated with high brittleness, indicating stiff and easily fractured rock. This information is important for fracking jobs as it dictates the amount of pressure needed to fracture the rock. A high 'brittleness' value translates to less pressure needed to frac the rock. Meanwhile, low brittleness value means that the rock is soft and flexible. In this case, a high amount of pressure is needed during hydraulic fracturing in order to frac the rock.

The log data above (Figure 33) shows that the Gamma Ray (GR) increases as it hits the top of the Marcellus Shale, which is expected due to the radioactive elements in the clay such as thorium, potassium and uranium. GR is a very useful logging tool to distinguish between shale and non-shale. The PR values are constant and do not fluctuate as it moves horizontally until it reaches a horizontal distance of 1070 meters 
(circled in red). There are few distinctive peaks throughout the well, circled in red dashed line. The rock layer above the Marcellus Shale is a non-shale rock that has high YME values and drops significantly as it reaches the top of the Marcellus Shale. The PR remains consistent throughout the layers, but the YME/PR ratio has reduced, which resulted in lower rock brittleness compared to the rock on top.

During the high peaks shown in red dashed circles, although the PR values do not change much, the YME has increased significantly at those points, thus resulting in high brittleness value. Table 2 below summarizes the PR, YME and brittleness values of those 5 peaks.

\begin{tabular}{|l|l|l|l|}
\hline Peak \# & PR & YME_Static (GPa) & Brittleness \\
\hline 1 & 0.22 & 5.18 & 23.55 \\
\hline 2 & 0.21 & 3.71 & 17.67 \\
\hline 3 & 0.21 & 4.49 & 21.38 \\
\hline 4 & 0.24 & 3.65 & 15.21 \\
\hline 5 & 0.27 & 3.59 & 13.29 \\
\hline
\end{tabular}

Table 2: Poisson's Ratio (PR), Young's Modulus(YME) and brittleness of peak 1-5

Since PR is a ratio, it is dimensionless and ranges between 0.1 to 0.45 . PR values of $0.1-0.25$ is considered low, which means that the rocks fracture easier. Values 
between $0.26-0.34$ is moderate and values between $0.35-0.45$ is considered high and that the rock is harder to fracture (Belyadi et al., 2019). Based on the table above, the PR value of peak 1 - 4 fall into low value category which means that the rock at that area fractures easily. At peak 5, the PR value of 0.27 mean that the rock is relatively harder to fracture. High YME value yield high rock brittleness (peaks 1, 2 and 3), low YME value yield low rock brittleness (peaks 4 and 5).

Changes in depth also affect the values of PR and YME. However, from the log data, the value of YME and PR vary across the Marcellus Shale although having the same depth. This shows that the fractures affect the geomechanical properties of the rock. 


\subsection{Conclusion}

3D seismic and well log data were used to test the hypothesis that the hydrocarbon productivity of the study area is linked to the structural complexity associated with faults and fractures. A detailed structural analysis of the seismic amplitude map showed regional faults associated with flat-top folds in the region.

The variation of fault and fracture orientations across the rock layers including the Marcellus Shale are affecting their productivity. The almost vertical west-trending strike-slip faults split through the rock layers from the topmost Tully Limestone to the base of Salina Salt. Based on the maximum curvature maps, the faults are most visible on Tully Limestone and slightly diminishing towards the older rocks. The east-trending reverse faults are the most visible on the older rock, Onondaga Limestone, and disappear towards the younger rocks like Tully Limestone. This indicates that the reverse faults are relatively older than the strike-slip faults.

The Marcellus Shale in Clearfield is heavily fractured and can be associated with its brittleness. Using the Poisson's Ratio (PR) and Young's Modulus (YME) calculated from the well logs, it is evident that Marcellus shale has high brittleness compared to the overlying rock resulting in abundant natural fractures. These features can be desirable for hydraulic fracturing but can also have an adverse effect on production depending on the fracture type, fracture fill and other fracture morphology. The changes in PR and YME across the rock shows that Marcellus Shale in Clearfield can be considered anisotropic. 
The dip angle maps show that the fracture dip angles are comparatively high and abundant on Marcellus Shale. Drilling unconventionally or fracking may not be a good approach since the rock is heavily disrupted and may have had released the hydrocarbon already.

The ant-tracking attributes further gave evidence of intense fracturing by way of fracture swarms. It shows that the vertical faults and fractures had created pathways for the leakage of oil and gas. The networking of those fractures is extensive and encourages hydrocarbon flow. The fractures are also connected both horizontally and vertically across the rock layers making it impractical to drill well in this region. The intense fracturing can be linked to the brittleness of Marcellus Shale.

Although natural fractures provide permeability, it may also lead to leakage. That is why a thorough investigation of fractures and reservoirs using 3D seismic is important. Understanding the brittleness of rock is the key for successful unconventional drilling to avoid difficulties during fracking or damaging the equipment. Frac hit is the common problem where the wells being fracked communicates with the nearby wells and affecting their integrity. This problem may be overcome by investigating the geomechanical strength and brittleness of the rock. Incorporating both physical and geomechanical properties would substantiate our understanding of the reservoir thus increasing drilling efficiency and avoiding drilling failure. 


\subsection{Future Work}

Moving forward, there is a lot of research potential in the Clearfield County reservoir. This study area is an excellent opportunity for researchers to further investigate the properties of a poor reservoir to reduce the exploration risk and increase the drilling effectiveness of other high potential reservoirs. The geomechanical properties such as Young's Modulus and Poisson's Ratio were observed from one of the horizontal wells. This work may be done to the other wells as well to strengthen the conclusion made in this study.

This study focuses on the horizontal well, therefore future work for the vertical wells in the study area is highly recommended. The geomechanical properties as well as brittleness of the rock layers of multiple vertical wells would expand our knowledge on the variation between different formations temporally and spatially.

In addition to that, an attribute-based seismic facies classification using machine learning and neural network can also be done in this reservoir. This method uses unsupervised classification to cluster facies together in an attribute space. 


\subsection{References.}

Barnstone, D., 2014, Bend in Appalachian Mountain Chain Finally Explained:

NewsCenter, University of Rochester, www.rochester.edu/newscenter/the-bend-in-theappalachian-mountain-chain-is-finally-explained/.

Belyadi, H., Fathi, E., \& Belyadi, F. (2019). Rock mechanical properties and in situ stresses. Hydraulic Fracturing in Unconventional Reservoirs, 215-231. doi:10.1016/b978-0-12-817665-8.00013-8

Bowers, C., 2014, Analyzing fracture stimulation of middle Devonian strata in Clearfield county, Pennsylvania using a 3D geomechanical fault model and microseismic: Master's thesis, West Virginia University.

Donahoe, T., \& D. Gao, 2016, Application of 3D seismic attribute analysis to structure interpretation and hydrocarbon exploration southwest Pennsylvania, Central Appalachian Basin: A case study. Interpretation, 4(3), 1-15.

Emujakporue, G. O., \& Enyenihi, E. E. (2020). Identification of SEISMIC attributes for hydrocarbon prospecting of Akos Field, Niger Delta, Nigeria. SN Applied Sciences, 2(5). doi:10.1007/s42452-020-2570-1. 
Engelder, T., G. G. Lash, and R. S. Uzcátegui, 2009, Joint sets that enhance production from Middle and Upper Devonian gas shales of the Appalachian Basin: AAPG Bulletin, 93, 857-889, doi: 10.1306/03230908032.

Ettensohn, F. R., 1985, The Catskill delta complex and the Acadian orogeny: A model: GSA Special Papers, 201, 39-50.

Faill, R. T., 1998, A geologic history of the north-central Appalachians - Part 3: The Allegheny orogeny: American Journal of Science, 298, 131-179, doi: 10.2475/ajs .298 .2 .131 .

Faill, R. T. (1997). A geologic history of the north-central Appalachians; Part 1, Orogenesis from the Mesoproterozoic through the Taconic Orogeny: American Journal of Science, 297(6), 551-619.

Frey, M. G., 1973, Influence of Salina salt on structure in New York-Pennsylvania part of the Appalachian Plateau: AAPG Bulletin, 57, 1027-1037.

Gao, D., R. C. Shumaker, and T. Wilson, 2000, Along-Axis Segmentation and Growth History of the Rome Trough in the Central Appalachian Basin1: AAPG Bulletin, vol. 84, no. 1 , pp. 75-99. 
Gao, D., 2011, Latest developments in seismic texture analysis for subsurface structure, facies, and reservoir characterization: A review: Geophysics, 76, no. 2, W1-W13, doi: 10.1190/1.3553479.

Gao, D., E. Roberts, C.Geiger, and P. Sullivan, 2019, 3D Seismic Characterization for the Acadian Detachment and Wrench Faults in the Hinge of the Pennsylvania Salient, Central Pennsylvania: Implications for the Marcellus Shale Reservoir Integrity in the Appalachian Basin: SEG Technical Program Expanded Abstracts 2019, 2019.

Geiger, C., 2017, Seismic texture applied to well calibration and reservoir property prediction in the north central Appalachian Basin: Master's thesis, West Virginia University.

Geiger, C., and D. Gao, 2017, Seismic texture analysis applied to unconventional reservoir characterization and calibration: A case study in Central Pennsylvania, North Central Appalachian Basin: AAPG Annual Convention and Exhibition, Houston, Texas.

Gouw, J. A. De, et al. 2014, Reduced Emissions of CO2, NOx, and SO2from U.S. Power Plants Owing to Switch from Coal to Natural Gas with Combined Cycle Technology: Earths Future, vol. 2, no. 2, 2014, pp. 75-82.

Hart, B. S. (2008). Channel detection in 3-D seismic data using sweetness. AAPG Bulletin, 92(6), 733-742. 
Khajah, Y. (2020). Rock mechanical Properties in Shale Plays. West Virginia University: unpublished assignment.

Kulander, C. S., \& Ryder, R. T. (2005). Regional seismic lines across the Rome Trough and Allegheny Plateau of northern West Virginia, western Maryland, and southwestern Pennsylvania: U.S. Department of the Interior.

"Natural Gas Explained Use of Natural Gas." U.S. Energy Information Administration (EIA), 19 July 2019, https://www.eia.gov/energyexplained/natural-gas/use-of-naturalgas.php

Radovich, B. J., \&R. B. Oliveros, 1998, 3-D sequence interpretation of seismic instantaneous attributes from the Gorgon Field: The Leading Edge, 17(9), 1286-1293.

Roberts, A., 2001, Curvature attributes and their applica- tion to 3D interpreted horizons: First Break, 19, 85 - 100, doi: 10.1046/j.0263-5046.2001.00142.x.

Roberts, E., 2013, Structure segmentation and transfer faults in the Marcellus Shale, Clearfield County, Penn- sylvania: Implications for gas recovery efficiency and risk assessment using 3D seismic attribute analysis: Master's thesis, West Virginia University. 
Roberts, E., and D. Gao, 2013, Along-strike structure seg- mentation and cross-strike transfer faults in the Middle Devonian Marcellus Shale, Pennsylvania, Central Appalachian Basin: Implications for gas recovery efficiency and risk assessment using 3D seismic attribute analysis: 83rd Annual International Meeting, SEG, Expanded Abstracts, doi: 10.1190/segam2013-1309.1.

Sak, P. B., Gray, M. B. , and Ismat Z., 2014, Significance of the deformation history within the hinge zone of the Pennsylvania Salient, Appalachian Mountains: The Journal of Geology, 122, 367-380, doi: 10.1086/675907.

Sarem, M. N., and Riahi, M. A., 2020, Geomechanical Unit Modeling Using Seismic and Well Log Data in One of the Southwestern Iranian Oilfields, Journal of Petroleum Exploration and Production Technology, doi.org/10.1007/s13202-020-00962-w.

Shultz, C. H., 1999, The geology of Pennsylvania, in C. Schultz, ed., The geology of Pennsylvania: Pennsylvania Geological Survey, Special Publication 1, 286-297.

Slatt, R., 2011, Important Geological Properties of Unconventional Resource Shales, ResearchGate, doi: 10.2478/s13533-011-0042-2.

U.S. Primary Energy Consumption by Energy Source, 2018, U.S. Energy Information Administration (EIA), U.S. Energy Information Administration (EIA), 28 Aug. 2019, https://www.eia.gov/energyexplained/us-energy-facts/. 
Wheeler, R. L., 1980, Cross-strike-structural discontinuities: Possible exploration tool for natural gas in Appalachian overthrust belt: AAPG Bulletin, 64, 2166-2178.

Wang, G., and T. Carr, 2013, Organic-rich Marcellus Shale lithofacies modeling and distribution pattern analysis in the Appalachian Basin: AAPG Bulletin, 97, 2173-2205, doi: 10.1306/05141312135.

Warpinski, Norman R., Branagan, Paul, and Roy Wilmer. "In-Situ Stress Measurements at U. S. DOE's Multiwell Experiment Site, Mesaverde Group, Rifle, Colorado." J Pet Technol 37 (1985): 527-536. doi: https://doi.org/10.2118/12142-PA

Zelenika, K. N., K. N. Mavar, \& S. Brnada, 2018, Comparison of the Sweetness Seismic Attribute and Porosity-Thickness Maps, Sava Depression, Croatia: Geosciences, 8(11), 426. 